Brazilian Journal

of Chemical

ISSN 0104-6632

Engineering

\title{
DEVELOPMENT OF A START-UP OPERATION AND DYNAMIC BEHAVIOR OF A THERMALLY COUPLED EXTRACTIVE DISTILLATION SCHEME
}

\author{
A. L. U. Vasconcelos ${ }^{1 *}$, M. F. Figueirêdo ${ }^{2}$, S. K. S. Carmo ${ }^{3}$, \\ W. B. Ramos ${ }^{2}$, L. G. S. Vasconcelos ${ }^{2}$ and R. P. Brito ${ }^{2}$ \\ ${ }^{1}$ Universidade Federal da Paraíba, Centro de Tecnologia e Desenvolvimento Regional, João Pessoa, PB, Brasil. \\ E-mail: angelalucinia@yahoo.com.br, ORCID: 0000-0002-2968-1060 \\ ${ }^{2}$ Universidade Federal de Campina Grande, Campina Grande, PB, Brasil. \\ ${ }^{3}$ Universidade Federal Rural do Semi-Árido, Pau dos Ferros, RN, Brasil.
}

(Submitted: February 7, 2018 ; Revised: July 14, 2018 ; Accepted: August 20, 2018)

\begin{abstract}
The startup operation of distillation columns is one of the most complex steps performed in the industry. This complexity becomes even greater for thermally coupled extractive distillation systems. Thermally coupled configurations are commonly used in order to minimize the excessive amount of energy required to perform distillation. In view of this, this study aimed to develop a startup procedure for the thermally coupled extractive distillation system to obtain anhydrous ethanol by simulation using the computational package Aspen Plus Dynamics. From the startup procedure developed, the complex dynamic behavior of the system under study was analyzed (strong interaction between variables). Large variations in the stripping section of the extractive column were observed, resulting from the variation of the molar density of the liquid mixture in addition to the delay in the startup operation when the amount of ethanol in the recovery column increases. Keywords: Startup; Thermally coupled extractive distillation; Dynamics.
\end{abstract}

\section{INTRODUCTION}

The operation of a continuous distillation column is periodically interrupted for maintenance procedures, which aim to ensure operational conditions so that equipment, facilities and services operate properly. After maintenance, the startup operation is initiated until the ongoing process achieves the desired steady state.

Depending on the operator or on the characteristics of the process, the startup operation of a distillation column may take several hours or even days to reach steady state. The longer the time required for the operation of the column to reach the steady state, the greater the amount of off-spec product and the greater the energy consumption, which reduces the process yield and increases the costs of operation.
The startup operation of a chemical processes and, in particular, distillation columns is very complex due to simultaneous changes in multiple variables relevant to the process (Kruse et al., 1996). The complexity of the operation may be observed from the dynamic behavior of the distillation column during the startup operation (Ruiz et al., 1988). This complexity becomes greater for systems comprising two or more distillation columns, such as in the extractive distillation system under study, which consists of an extractive distillation column and a solvent recovery column.

Distillation is one of the most used separation processes in the chemical industry, although it has the disadvantage of requiring high energy consumption. In order to reduce the high energy consumption, several researchers have presented approaches for distillation. Some of the approaches presented in the literature are

\footnotetext{
* Corresponding author: A. L. U. Vasconcelos - E-mail: angelalucinia@yahoo.com.br
} 
about modifications in design, such as the thermally coupled distillation columns system. The thermally coupled system consists of two distillation columns interconnected by a stream in the vapor phase and another stream in the liquid phase. Each interconnection replaces a condenser or a reboiler from one of the columns. This configuration can result in a reduction in energy consumption of up to $30 \%$ compared to the conventional configuration (Gutiérrez-Guerra, 2008; Segovia-Hernández et al., 2009; Long e Lee, 2013).

The startup operation is a great important step in chemical plants. However, it was observed that just a few researches about this subject have been published. Most of the researches are about design, optimization and control of the distillation operation (Yasuoka et al., 1987; Ruiz et al., 1988; Fieg et al., 1993; Barolo et al., 1994; Sorensen e Skogestad, 1996; Kruse et al., 1996; Wang et al., 2003; Wendt et al., 2003; Elgue et al., 2004). Additionally, no researches related to startup operation of thermally coupled extractive distillation systems have been reported in the literature. So, the main contribution of this work is the presentation of a startup procedure for a thermally coupled extractive distillation system. More specifically, the aim of this work was to develop a startup procedure, through simulation, for a thermally coupled extractive distillation system used to separate the azeotropic ethanol-water mixture with ethylene glycol as solvent. The simulator used was the commercial software Aspen Plus.

\section{GENERAL METHODOLOGY}

\section{Steady-State Modeling}

Initially, the model was built in Aspen Plus in steady state. The chemical components used in the simulation were ethanol, water, ethylene glycol and nitrogen. Although nitrogen was specified in this step, this component was only used in Aspen Plus Dynamics as an inert gas.

The thermodynamic model used in this work for the calculation of the liquid phase activity coefficient was NRTL. Figueiredo (2003) confirmed the good representativity of the data estimated by the NRTL model for the ethanol/water system by presenting the comparison of the xy and T-xy diagrams for the ethanol/water mixture at $1 \mathrm{~atm}$ of pressure considering the experimental data presented in the literature and the values estimated by the Aspen Plus simulator. Hadrich and Kechaou (2010) investigated the fitting of the liquid-vapor equilibrium of ethanol-water mixtures at atmospheric pressure from four thermodynamic models and concluded that the NRTL model is the best one for fitting equilibrium data. Considering that the studied system operation is carried out under atmospheric pressure, the vapor phase can be considered ideal. Therefore, the thermodynamic model determined for the vapor phase was the ideal gas law.

The system under study (Figure 1) consisted of two distillation columns interconnected by two streams. One stream in the vapor phase (VAP) and another in the liquid phase (LIQ), which characterizes the thermal coupling between columns. The VAP stream leaves from stage 24 of column 1 and enters in stage 5 of column 2. The LIQ stream returns to stage 25 of column 1 from stage 5 of column 2 .

The extractive distillation column (COL1) is used to separate the azeotropic mixture ethanol-water using ethylene glycol as solvent. The second column (COL2) is the solvent recovery column and its top product is water. The RadFrac routine from Aspen Plus was

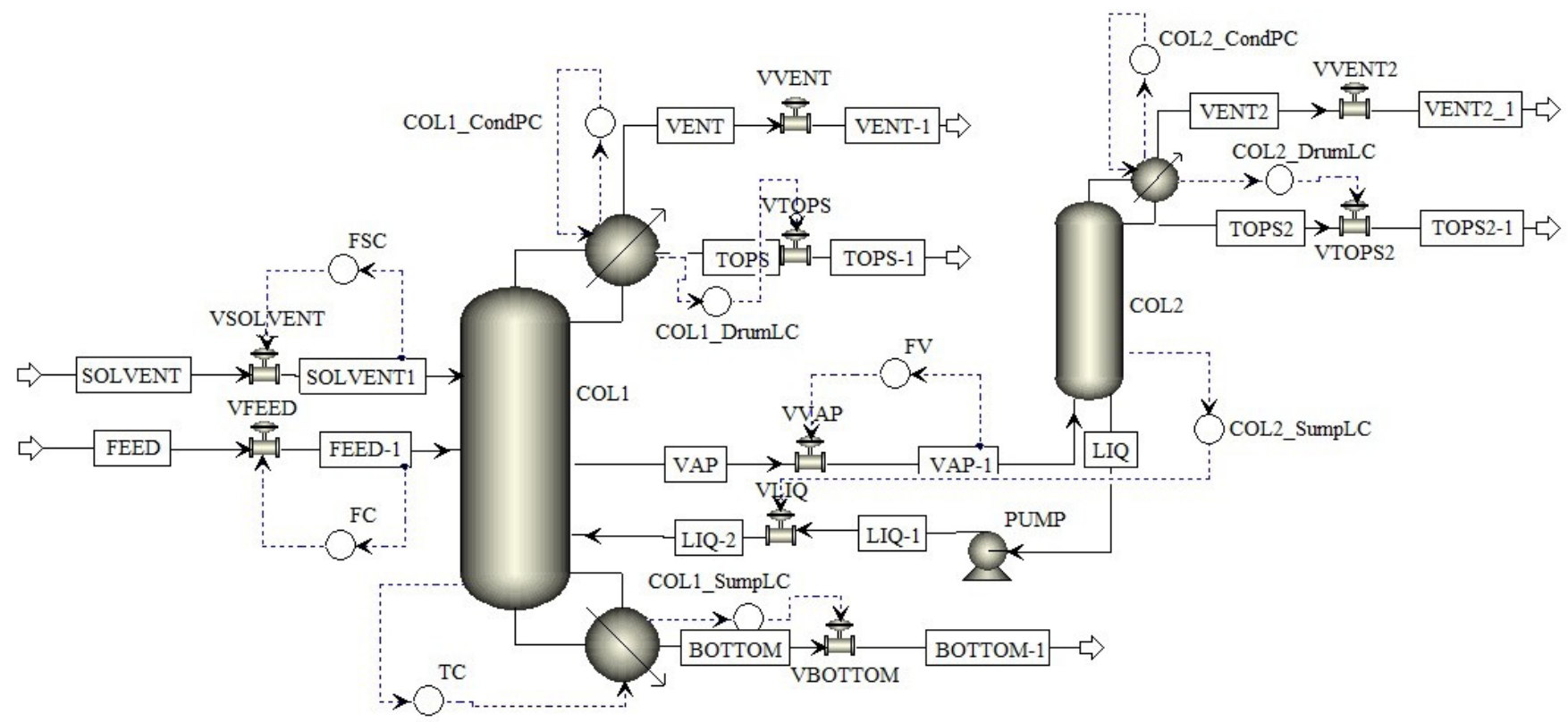

Figure 1. Thermally coupled columns flowsheet. 
used for both columns, which constituted a rigorous modeling based on equilibrium stages. Due to the connection between streams, the reboiler of the second column was removed. Streams were added in both condensers (VENT and VENT2) in order to carry out the inert nitrogen gas purge in Aspen Plus Dynamics. The physical properties specifications (Table 1) of the feed streams (FEED and SOLVENT) and operational conditions (Table 2) of the distillation columns were based on the research of Brito (2014).

Table 1. Input streams specifications.

\begin{tabular}{lcc}
\hline \multirow{2}{*}{ Parameters } & \multicolumn{2}{c}{ Streams } \\
\cline { 2 - 3 } & FEED & SOLVENT \\
\hline Temperature $\left({ }^{\circ} \mathrm{C}\right)$ & 40 & 40 \\
Pressure $($ bar) & 7 & 3 \\
Mass flowrate $(\mathrm{kg} / \mathrm{h})$ & 4186.1 & 5586.16 \\
Mass fraction of ethanol & 0.935 & 0 \\
Mass fraction of water & 0.065 & 0 \\
Mass fraction of ethylene glycol & 0 & 1 \\
Mass fraction of nitrogen & 0 & 0 \\
\hline
\end{tabular}

Table 2. Operational conditions of columns 1 and 2.

\begin{tabular}{lcc}
\hline \multicolumn{1}{c}{ Parameters } & COL1 & COL2 \\
\hline Number of stages & 29 & 5 \\
Solvent feed stage & 4 & - \\
Azeotrope feed stage & 16 & - \\
COL2 feed stage & - & 5 \\
Top pressure (bar) & 1 & 0.6 \\
Pressure drop (bar) & 0.2 & 0.1 \\
Reflux ratio & 0.6 & 1.14 \\
Bottom stream mass flow rate $(\mathrm{kg} / \mathrm{h})$ & 5587.8 & 303.165 \\
\hline
\end{tabular}

\section{Dynamic Modeling}

Since the model must be exported to Aspen Dynamics, it is necessary to specify the dynamic settings of the condensers and reboiler, the geometric characteristics of the reflux vessels and base of the columns, as well as the hydraulic characteristics of the trays of the columns.

The condensers of columns 1 and 2 were specified with the heat transfer option, using the Logarithmic Mean Temperature Difference (LMTD) approach, where the temperature of the cooling medium, water, was specified as $20{ }^{\circ} \mathrm{C}$. The difference between the process fluid temperature and cooling water outlet temperature was specified as $10{ }^{\circ} \mathrm{C}$. The heat transfer option was chosen so that the variable coolant flowrate, at Aspen Dynamics, was available during the choice of manipulated variable for pressure control.

The reboiler of column 1 was specified with the option "condensation of the heating medium", namely water vapor. This heat transfer option was chosen in order to make available the heating medium flowrate as a manipulated variable to control the temperature of the column in Aspen Dynamics.

The geometric characteristics of the columns are shown in Table 3 and the tray hydraulics parameters are shown in Table 4.
Table 3. Geometric characteristics of columns 1 e 2

\begin{tabular}{lcc}
\hline \multicolumn{1}{c}{ Parameters } & COL1 & COL2 \\
\hline Reflux vessel length $(\mathrm{m})$ & 2 & 2 \\
Reflux vessel diameter $(\mathrm{m})$ & 1 & 1 \\
Bottom section height $(\mathrm{m})$ & 2 & 1.9 \\
Bottom section diameter $(\mathrm{m})$ & 2 & 0.936 \\
\hline
\end{tabular}

Table 4. Tray hydraulics parameters of columns 1 e 2.

\begin{tabular}{lcc}
\hline \multicolumn{1}{c}{ Parameters } & COL1 & COL2 \\
\hline Diameter of the trays $(\mathrm{m})$ & 2 & 0.936 \\
Spacing $(\mathrm{m})$ & 0.6096 & 0.6096 \\
Weir height $(\mathrm{m})$ & 0.05 & 0.05 \\
\% Active area & 90 & 90 \\
Hole diameter $(\mathrm{m})$ & 0.0254 & 0.0254 \\
\% Downcomer escape area & 10 & 10 \\
\hline
\end{tabular}

After defining the dynamics settings of the model and rerunning the simulation, the model is ready to be exported to Aspen Dynamics. In some simulations, it is necessary to take into account the effect of the downstream pressure on the stream flowrates. To take this effect into account, it is necessary to create a Pressure Driven simulation. In this paper, the Pressure Driven approach was used.

When exporting the model from Aspen Plus to Aspen Dynamics, all the controllers must be added and have their parameters adjusted, as can be seen in Figure 1. The pressure controller COL1_CondPC has the pressure of Stage 1 of COL1 as process variable and the cooling water flowrate in the condenser of COL1 as manipulated variable. The pressure controller COL2_CondPC has the pressure of Stage 1 of COL2 as process variable and the cooling water flowrate in the condenser of COL2 as manipulated variable.

The controller COL1_DrumLC has the reflux vessel level of column 1 as process variable and the opening position of the valve VTOPS as manipulated variable. The controller COL1_SumpLC has the sump level of column 1 as process variable and the opening position of the valve VBOTTOM as manipulated variable. The controller COL2_DrumLC has the reflux vessel level of column 2 as process variable and the opening position of the valve VTOPS2 as manipulated variable.

The controller FC has the mass flow rate of Feed1 stream as process variable and the opening position of the VFEED valve as manipulated variable. The controller FSC has the mass flowrate of the stream SOLVENT1 as process variable and the opening position of the valve VSOLVENT as the manipulated variable. In the controller PV, the mass flow rate of VAP-1 stream is the process variable and the opening position of the valve VVAP as the manipulated variable.

The controller TC has the temperature of stage 24 as process variable and the heating steam flowrate in reboiler as the manipulated variable. The controller 
COL2 SumpLC has the sump level of column 2 as process variable and the opening position of the valve VLIQ as the manipulated variable. The controller setting parameters are shown in Table 5.

On Aspen Plus Dynamics, the column is started in a cold and empty condition. There is a pre-built script called "Empty" that is used in Aspen Plus Dynamics to reset the column to this empty and cold state. In fact, the column is not emptied, which would cause a vacuum inside the column. Thus, when runnig the script Empty, the column is filled with the inert gas nitrogen at $20^{\circ} \mathrm{C}$ and pressure of 1 bar. Therefore, the nitrogen must be specified along with other chemical components in the simulation model prior to being exported from Aspen Plus.

Before running the script "Empty", the VVENT and VVENT2 purge valves must be fully closed. After running the script "Empty", all controllers are placed in manual mode and the output signals of the controllers are adjusted to their minimum values.

After adjusting the controllers in manual mode, the execution mode "inicialization" can be executed. After performing these steps, a "Task" must be added to the model. The "Task" is a sequence of actions specified by the user, which are made by the simulator at a given time, that is, the "Task" contains all steps for the starting procedure. The "Task" should be developed using the programming language of Aspen Plus Dynamics. Finally, the execution mode is changed to "dynamic" and the simulation is performed.

Table 5. Controllers settings parameters.

\begin{tabular}{lccc}
\hline \multirow{2}{*}{ Controllers } & \multicolumn{3}{c}{ Tuning parameters } \\
\cline { 2 - 4 } & Gain & $\begin{array}{c}\text { Integral } \\
\text { (min) }\end{array}$ & $\begin{array}{c}\text { Derivative } \\
\text { (min) }\end{array}$ \\
\hline COL1_CondPC & 10 & 12 & 0 \\
COL2_CondPC & 10 & 12 & 0 \\
FC & 1 & 0.5 & 0 \\
FSC & 1 & 0.5 & 0 \\
FV & 1 & 0.5 & 0 \\
TC & 1 & 20 & 0 \\
COL1_DrumLC & 10 & 60 & 0 \\
COL1_SumpLC & 10 & 60 & 0 \\
COL2_DrumLC & 10 & 60 & 0 \\
COL2_SumpLC & 10 & 60 & 0 \\
\hline
\end{tabular}

\section{STARTUP PROCEDURE DEVELOPED}

In this paper, the procedures developed were based on a sequence of basic actions proposed by Ruiz et al. (1988). The sequence of actions corresponds mainly to the opening and closing of valves during all of the startup operation. Different from Ruiz et al. (1988), who proposed a startup procedure for only one distillation column, in this work a startup procedure was proposed for a system composed of two thermally coupled distillation columns.

To develop a startup procedure, it is necessary to specify a sequence of basic actions in the Task, with the programming language of Aspen Dynamics and watch the effect of the actions on the dynamic behavior of the key variables of the system. From the observations, the sequence of actions is amended to attain the right dynamic behavior for the startup operation.

From various simulations of startup procedures, observations and adjustments in the sequence of actions, a starting procedure called PP1 was developed that is suited to a thermally coupled extractive distillation system, in a study that reflected in a lower total startup time.

The startup procedure PP1 developed can be represented, in summary, by the following sequence of actions:

At time $\mathrm{t}=0 \mathrm{hr}$, COL1 is empty and cold and the azeotropic mixture ethanol-water and the solvent ethylene are introduced gradually. It should be emphasized that, during the procedure, the feed flowrates of the ethanol-water mixture and ethylene glycol are increased gradually until reaching their steady state values.

- At time $\mathrm{t}=0.87 \mathrm{hr}$, the liquid reaches the bottom of column COL 1 and it begins to increase.

- At time $\mathrm{t}=2.03 \mathrm{hr}$, the liquid level at the bottom of COL1 reaches the value of $0.34 \mathrm{~m}$ and the pressure control of COL1 is placed in automatic mode with the setpoint adjusted at 1 bar.

- At time $\mathrm{t}=2.13 \mathrm{hr}$, the heating steam begins to be introduced into the reboiler, so that the liquid in the bottom begins to vaporize and the steam generated in COL1 begins to ascend. It should be emphasized that, during the startup procedure, the flowrate of the heating steam is gradually increased until it reaches the steady state value.

- At time $\mathrm{t}=2.14 \mathrm{hr}$, nitrogen purge valve of COL1 is completely opened.

- At time $t=2.63 \mathrm{hr}$, nitrogen purge valve of COL1 begins to be gradually closed.

- At time $\mathrm{t}=2.8 \mathrm{hr}$, the level in the reflux vessel reaches the value of $0.5 \mathrm{~m}$ and the reflux is started in COL1.

- At time $\mathrm{t}=7.54 \mathrm{hr}$, the mass fraction of water in stage 24 from COL1, determining when the feed stream of COL2 is connected, reaches the value 0.8 and feeding of COL2 is initiated.

- At time $t=7.69 \mathrm{hr}$, pressure control of COL2 is placed in automatic mode with the set point adjusted to 0.6 bar.

- At time $t=7.74 \mathrm{hr}$, nitrogen purge valve of COL2 is fully opened.

- At time $\mathrm{t}=8.06 \mathrm{hr}$, nitrogen purge valve of COL2 is closed.

- At time $\mathrm{t}=11.76 \mathrm{hr}$, the flowrate controlers of the ethanol-water mixture and ethylene glycol are adjusted to their steady state values. 
- At time $\mathrm{t}=12.01 \mathrm{hr}$, the temperature control of COL1 is placed in automatic mode with the set point adjusted to $170.49^{\circ} \mathrm{C}$.

- At time $\mathrm{t}=13.01 \mathrm{hr}$, the reflux vessel level of COL2 reaches the value of $0.5 \mathrm{~m}$ and the reflux is started.

- At time $t=14.54 \mathrm{hr}$, the base level of COL2 reaches the value of $0.8 \mathrm{~m}$ and the valve VLIQ starts to open gradually and the base product from COL2 returns to COL1.

- At time $\mathrm{t}=22.63 \mathrm{hr}$, Steady state specifications are achieved.

As in Weng and Leo (2014), the end of the startup operation is determined when the mass fractions of the products satisfy Equation 1. Where, $X_{p, i}$ is the mass fraction of component $i$ in the product stream $p, X_{p, i s s}$ is the mass fraction of component $i$ in the product stream $p$ at steady state.

$\left|\mathrm{X}_{\mathrm{p}, \mathrm{i}}-\mathrm{X}_{\mathrm{p}, \mathrm{iss}}\right| \leq 0.001$

Therefore, Equation 1 was applied to the distillate stream of COL1, whose component $i$ is ethanol, to the base stream of COL1, whose component $i$ is ethylene glycol and to the distillate stream of COL2, whose component $i$ is water. The values of $X_{p, i s s}$ were obtained from the steady state simulation. Figure 2 represents the graph of Equation 1 applied to the product streams of COL1 and COL2, for the procedure PP1.

From Figure 2, it can be observed that, although the top product stream TOPS-1 from COL1 reaches a condition lower than 0.001 at the time $\mathrm{t}=3.45 \mathrm{hr}$, COL1 only reaches the steady state at time $t=12.76$ $\mathrm{h}$, that is, when Equation 1 reaches the condition lower than 0.001 in the base product stream BOTTOM-1. Likewise, COL2 only reaches steady state at the time $\mathrm{t}=22.63 \mathrm{hr}$. Therefore, COL2 determines the total startup time of the thermally coupled extractive

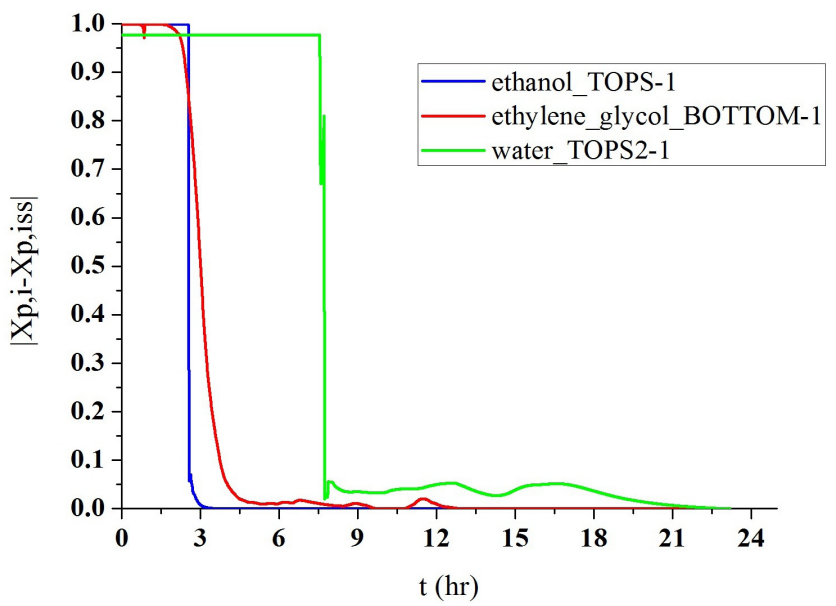

Figure 2. Determination of Total Startup Time for PP1. distillation columns system under study since it is the last to reach steady state.

During the development of the procedure PP1, it was observed that the second column demanded more time to complete the startup. In order to reduce this startup time, the first column was started only after a certain time, 7.54 hours, and then the startup operation of the second column was initiated. This strategy was adopted so that the feed conditions of the second column were closer to the steady state conditions, thus reducing the startup time of the second column and therefore of the system. To demonstrate this strategy, the same startup procedure PP1 was applied by changing only the initial startup time of the second column, that is, the startup of the second column was initiated at $t$ $=2.73 \mathrm{~h}$, before the feeding conditions were close to the steady state conditions. This procedure was named PP2.

The startup procedure PP2 comprises the following sequence of actions:

At time $\mathrm{t}=0 \mathrm{hr}$, COL1 is empty and cold and the azeotropic mixture ethanol-water and the solvent ethylene glycol are introduced gradually. It should be emphasized that, during the procedure, the feed flowrates of the ethanol-water mixture and ethylene glycol are increased gradually until reaching their steady state values.

At time $\mathrm{t}=0.87 \mathrm{hr}$, the liquid reaches the bottom of column COL1 and it begins to increase.

At time $\mathrm{t}=2.03 \mathrm{hr}$, the liquid level at the bottom of COL1 reaches the value of $0.34 \mathrm{~m}$ and the pressure control of COL1 is placed in automatic mode with the setpoint adjusted to $1 \mathrm{bar}$.

At time $\mathrm{t}=2.13 \mathrm{hr}$, the heating steam begins to be introduced into the reboiler, so that the liquid in the bottom begins to vaporize and the steam generated in COL1 begins to ascend. It should be emphasized that, during the startup procedure, the flowrate of the heating steam is gradually increased until it reaches the steady state value.

- At time $\mathrm{t}=2.14 \mathrm{hr}$, nitrogen purge valve of COL1 is completely opened.

- At time $\mathrm{t}=2.63 \mathrm{hr}$, nitrogen purge valve of COL1 begins to be gradually closed.

- At time $\mathrm{t}=2.73 \mathrm{hr}$, the feeding of COL2 is initiated.

- At time $\mathrm{t}=2.8 \mathrm{hr}$, the level in the reflux vessel reaches the value of $0.5 \mathrm{~m}$ and the reflux is started in COL1.

- At time $\mathrm{t}=2.89 \mathrm{hr}$, pressure control of COL2 is placed in automatic mode with the set point adjusted to 0.6 bar.

- At time $\mathrm{t}=2.96 \mathrm{hr}$, nitrogen purge valve of COL2 is fully opened.

- At time $\mathrm{t}=4.24 \mathrm{hr}$, nitrogen purge valve of COL2 is closed. 
- At time $t=8.27 \mathrm{hr}$, the reflux vessel level of COL2 reaches the value of $0.5 \mathrm{~m}$ and the reflux is started.

- At time $\mathrm{t}=11.08 \mathrm{hr}$, the base level of COL2 reaches the value of $0.8 \mathrm{~m}$ and the valve VLIQ starts to open gradually and the base product from COL2 returns to COL1.

- At time $t=11.76 \mathrm{hr}$, the flowrate controlers of the ethanol-water mixture and ethylene glycol are adjusted to their steady state values.

- At time $\mathrm{t}=12.01 \mathrm{hr}$, the temperature control of COL1 is placed in automatic mode with the set point adjusted to $170.49^{\circ} \mathrm{C}$.

- At time $\mathrm{t}=38.87 \mathrm{hr}$, Steady state specifications are achieved.

Figure 3 shows the total time of the startup procedure PP2. From Figure 3, it can be observed that, when the startup operation of the second column is conducted before the steam feed conditions reach steady state, as in procedure PP2, the startup time of the second column rises to $40.98 \mathrm{~h}$. Therefore, it is proved that the second column should be fed when the steam feed conditions are close to the steady state conditions. So, in order to reduce the startup time of column 2 and consequently the total startup time of the system, it is necessary that the conditions of the vapor that leaves from column 1 and is fed to column 2 through the VAP-1 chain stay as close as possible of the steady state conditions.

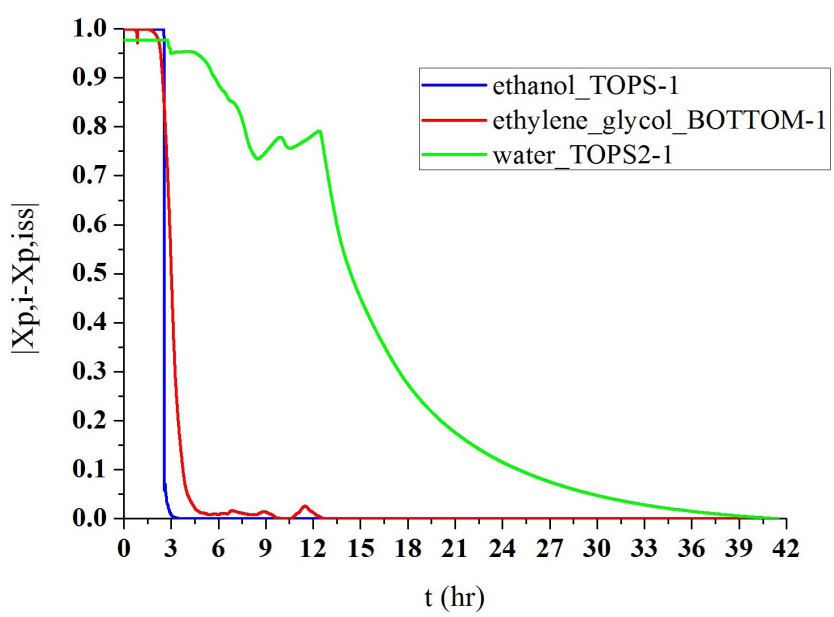

Figure 3. Determination of the Total Startup Time for PP2.

\section{DYNAMIC BEHAVIOR}

\section{Dynamic behavior of column 1 (COL1)}

Figure 4 shows the dynamic behavior of temperature (Figure $4 a$ ) and pressure (Figure $4 b$ ) at several stages of the rectification section (stages 2, 6, 10, 14) and several stages of the stripping section (stages 18, 22 and 26) of the extractive column during the startup operation. It was observed that, at the beginning of the

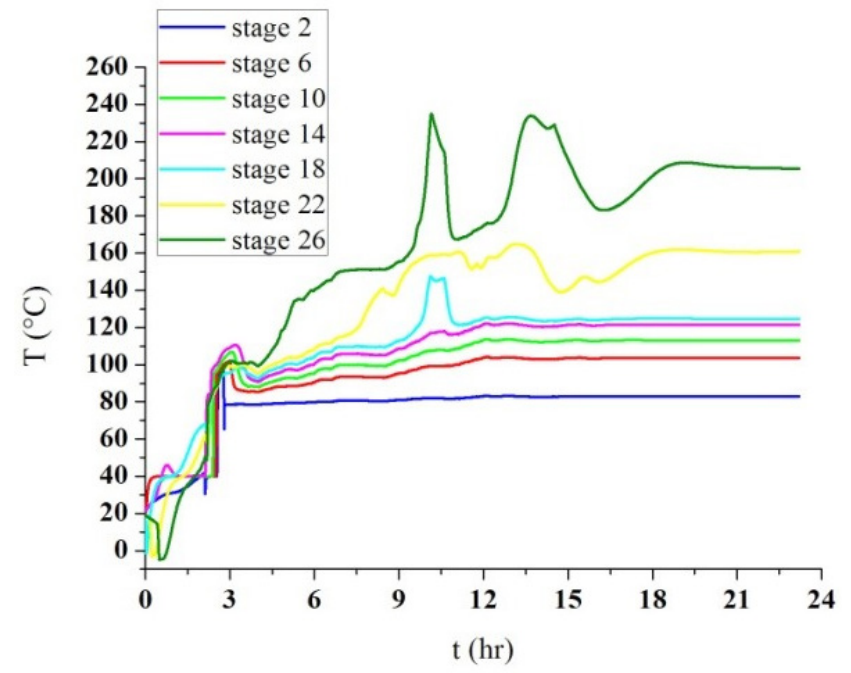

(a)

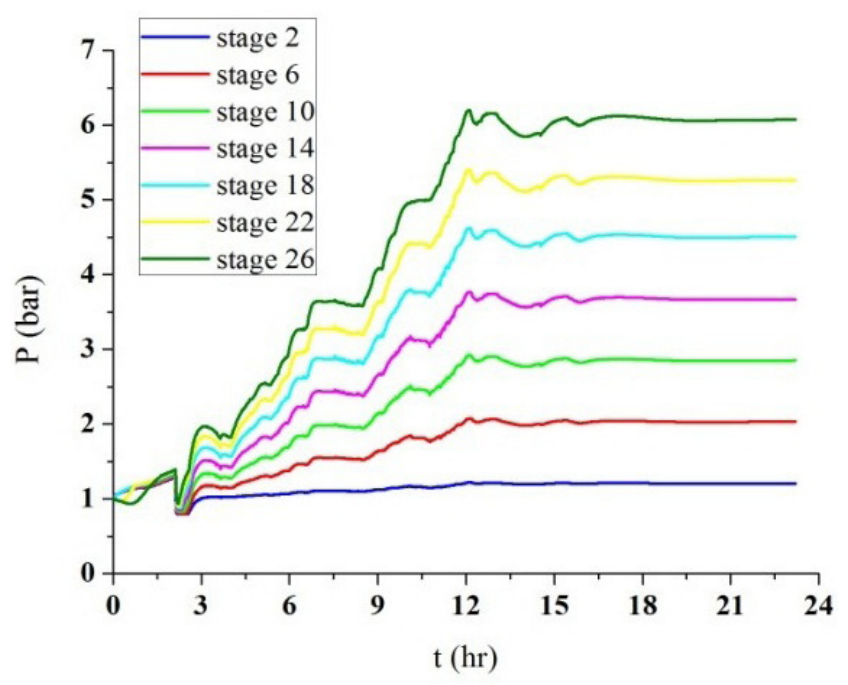

(b)

Figure 4. Dynamic behavior of (a) temperature and (b) Pressure of several stages in COL1.

startup operation, the stages located in the stripping section undergo a sharp drop in temperature, and then the temperature increases until reaching the feed temperature of the azeotropic mixture, $40{ }^{\circ} \mathrm{C}$. In the following moments, the temperatures of the stages increase with the increase of the reboiler steam flowrate and undergo a slight drop due to reflux. The temperatures of the stages located in the stripping section are more vulnerable to larger disturbances than the stages located in the rectification section.

According to Kister (1990), when the distillation column is pressurized with an inert gas and the liquid feed is introduced into the column, a temperature drop occurs throughout the stages of the column until the boiling liquid reaches the equilibrium conditions with the condensing steam. When the column contains an inert gas, the equilibrium is achieved when the partial pressure of the evaporated liquid increases enough 
in the vapor space. Until that moment, the flash temperature is much lower than the bubble point, at the column pressure, at the feeding. This behavior was observed in the simulated system as shown in Figure 4 (a).

In Figure 4(b) it is observed that, at the beginning of the startup operation, the pressure of the stages falls slightly and then increases due to the feed of the azeotropic mixture and solvent. When the purge valve VVENT is opened, the pressure of the stages undergoes an abrupt decrease until the moment that the heating steam begins to be fed to the reboiler and the vapor generated inside COL1 begins to ascend throughout the stages. From that moment, the pressure of the stages and the pressure drop between stages begin to increase until they reach the steady state values, forming the observed pressure profile.

Figure 5 shows the dynamic behavior of the liquid flow in the orifices of several trays from COL1. It is observed that, during the first moments of the startup operation, liquid drips through the orifices of the trays and when, the liquid level on the tray becomes high enough, the liquid also begins to flow through the downcomers.

The trays begin to be completely sealed when steam starts to be generated in the reboiler and the steam begins to ascend throughout COL1, i.e., at the time $\mathrm{t}=2.22 \mathrm{hr}$. When the tray is sealed, the liquid only flows through the downcomers and the vapor ascends throughout COL1 only through the orifices of the trays. In stages 2 and 3, which are located above the solvent feed stage 4 , there is no liquid flow through the orifices of the trays since they only receive liquid from reflux and the trays are sealed before the reflux is started.

Figure 6(a) shows the dynamic behavior of the ascending vapor flow in COL1 during the startup operation. Figure 6(b) shows the dynamic behavior of

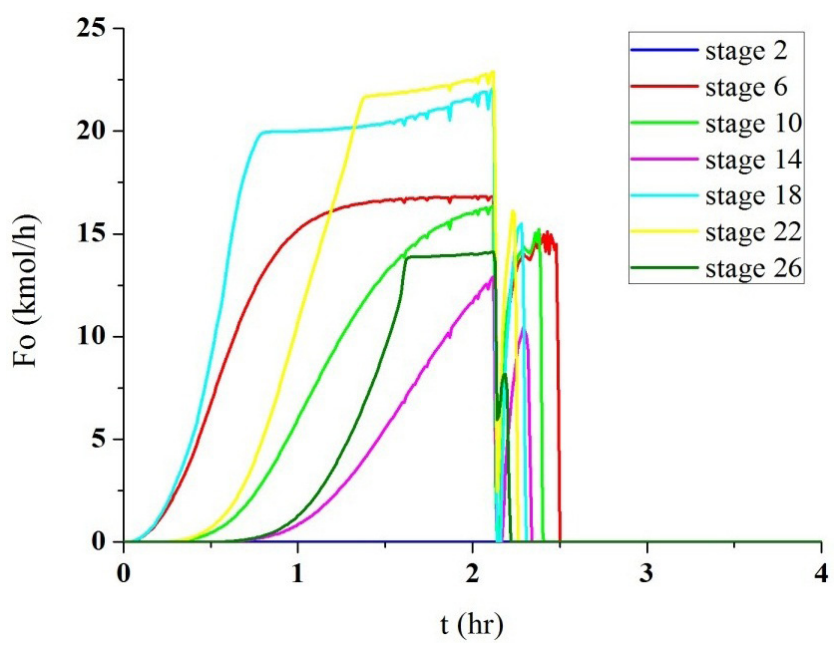

Figure 5. Dynamic behavior of the liquid flow in the orifices of several stages in COL1.

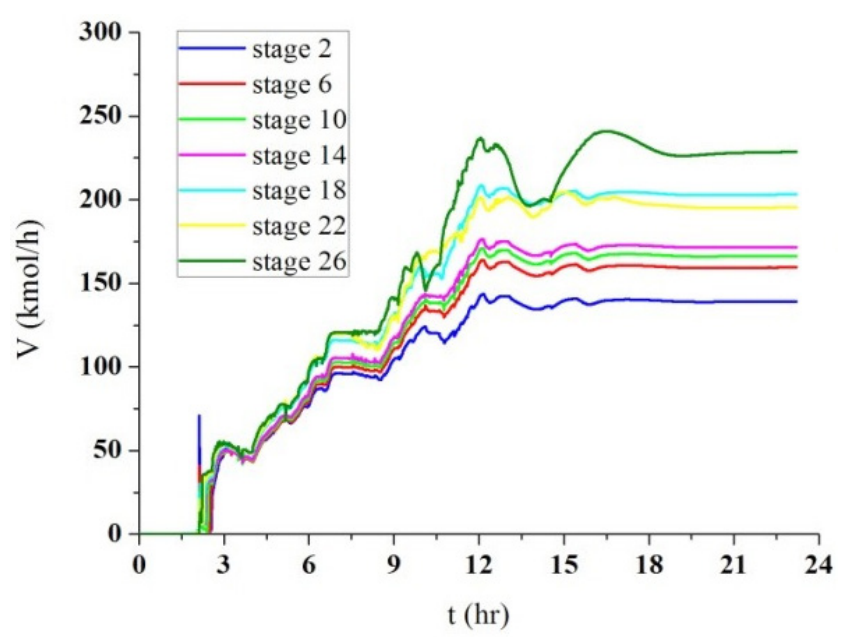

(a)

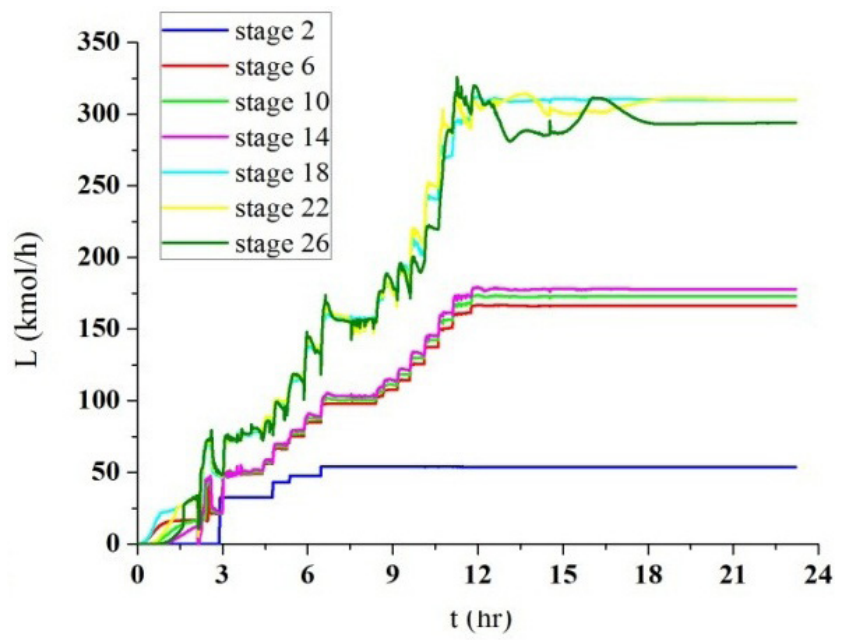

(b)

Figure 6. Dynamic behavior of (a) Steam Flow and (b) Liquid Flow of several stages in COL1.

the descending liquid flow in COL1 during the startup operation. In Figure 6(b), it is well established that the liquid flow in stages 2 and 3 , located above stage 4 , where the solvent is fed, is lower than in the other stages, as these stages are fed only by the reflux of COL1.

Among the stages 4 and 15, the liquid flow profile already has higher values because they receive liquid from the reflux and solvent feed stream. Between the stages 16 and 28, the liquid flow profile has the highest values for receiving the liquid from the reflux, from the solvent feed stream and from the azeotropic mixture feed stream. In Figure 6, it can be seen that the vapor flow profile and the liquid flow profile are influenced by the pressure profile throughout the stages of the column.

Figure 7(a) shows the dynamic behavior of the liquid holdup throughout the stages of the column and Figure 7(b) shows the dynamic behavior of the molar density of the liquid throughout the stages of the column during the startup operation. In Figure 7, 


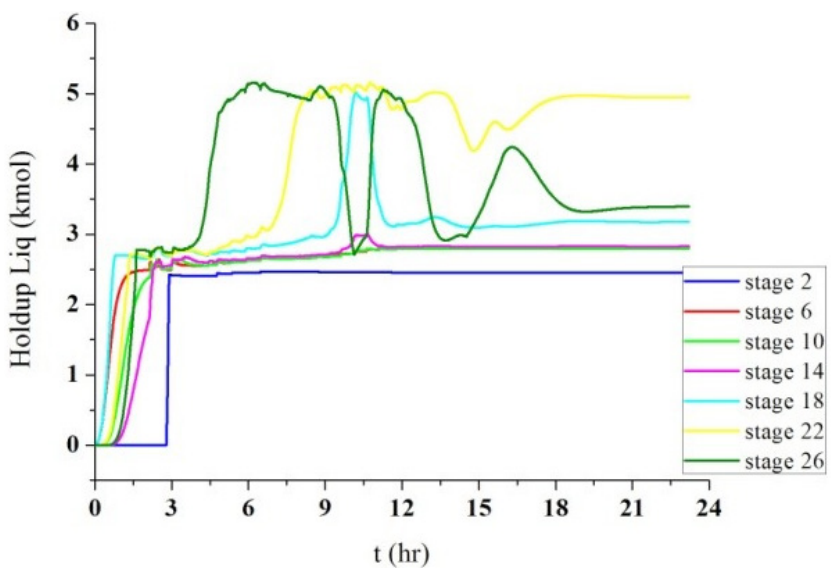

(a)

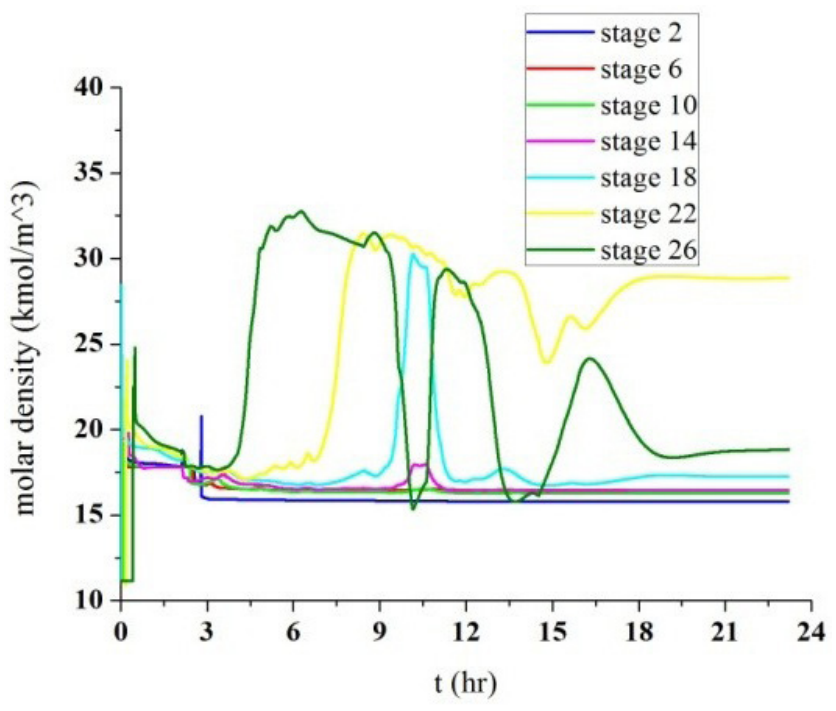

(b)

Figure 7. Dynamic behavior of (a) Liquid Holdup and (b) Liquid Molar Density of several stages in COL1.

it can be observed that the liquid holdup throughout the stages of the column is directly influenced by the liquid molar density in each stage.

Figure 8 shows the dynamic behavior of the mole fractions of the components in stages 2 located in COL1 rectification section.

At the beginning of the startup operation, a pressure drop occurs in the stages located in the stripping section, as seen in Figure 4(b). The pressure drop causes an increase in vapor flow throughout the stages located in the rectification section, as seen in Figure 6(a), and therefore the carrying of ethylene glycol to stages 2 and 3 of COL1. Thus, the liquid fraction of ethylene glycol in the second stage increases, as can be seen in Figure 8(a). When ethanol is vaporized and the vapor rich in ethanol reaches stages 2 and 3, a small portion of this vapor is condensed, and then the mole fraction of ethylene glycol in the liquid phase decreases as the mole fraction of ethanol in the liquid phase increases. Right after that, the reflux is started

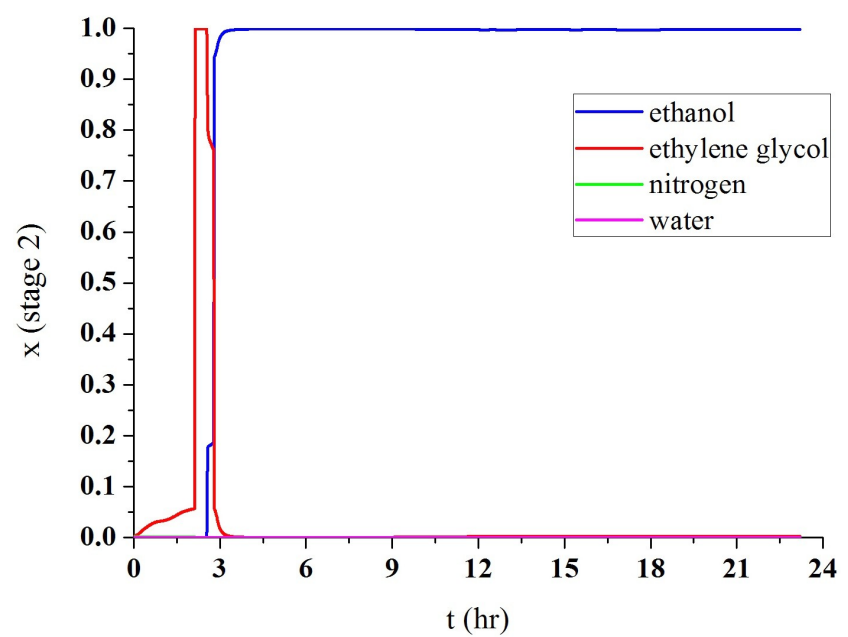

(a)

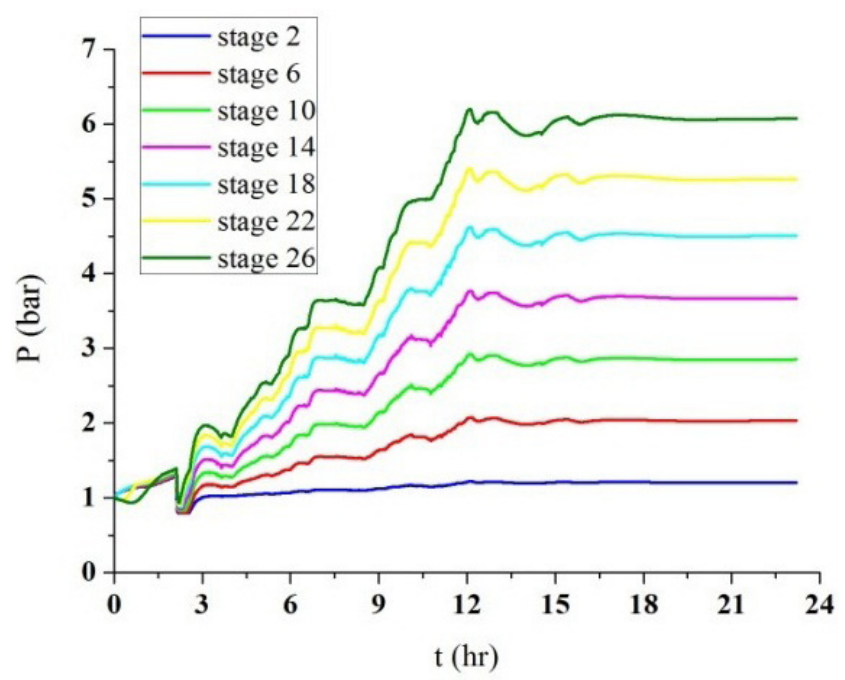

(b)

Figure 8. Dynamic behavior of the (a) liquid mole fraction and (b) vapor mole fraction in stage 2 in the rectification section of COL1.

and the stages 2 and 3 are filled with liquid ethanol and thus the molar fraction of the liquid phase reaches the maximum value for ethanol.

Figure 9 shows the dynamic behavior of the mole fractions of the components in stage 6 located in the COL1 rectification section.

Figure 10 shows the dynamic behavior of the mole fractions of the components in stage 10 located in the COL1 rectification section.

Figure 11 shows the dynamic behavior of the mole fractions of the components in stage 18 located in the stripping section of COL1. Figure 12 shows the dynamic behavior of the mole fractions of the components in stage 22 located in the stripping section of COL1. Figure 13 shows the dynamic behavior of the mole fractions of the components in stage 26 located in the stripping section of COL1.

It is observed that the profiles of the variables in the stages located in the stripping section of the column 


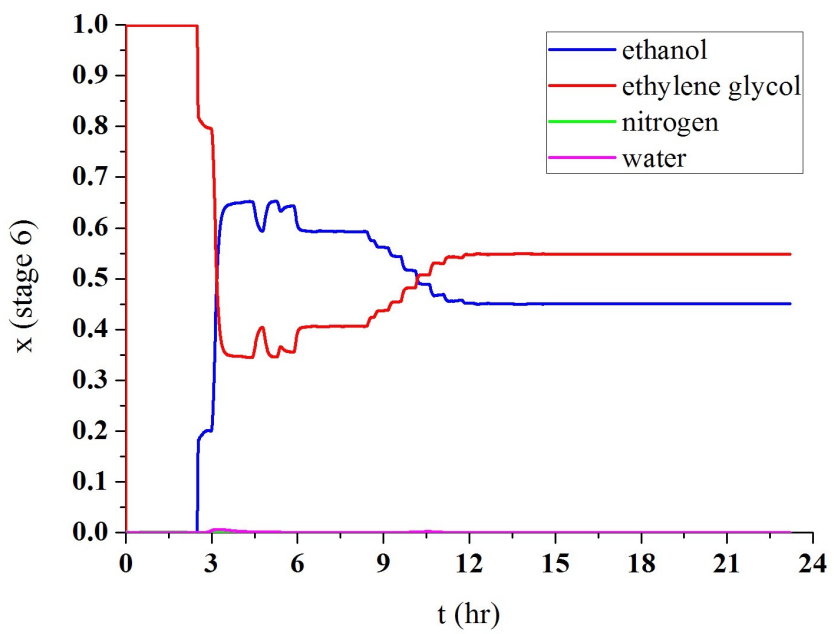

(a)

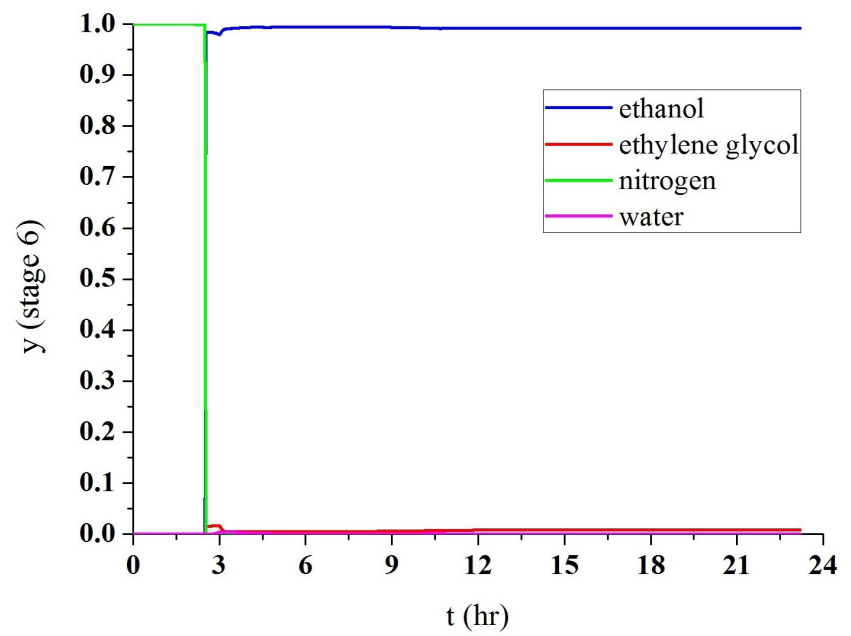

(b)

Figure 9. Dynamic behavior of the (a) liquid mole fraction and (b) vapor mole fraction in stage 6 in the rectification section of COL1.

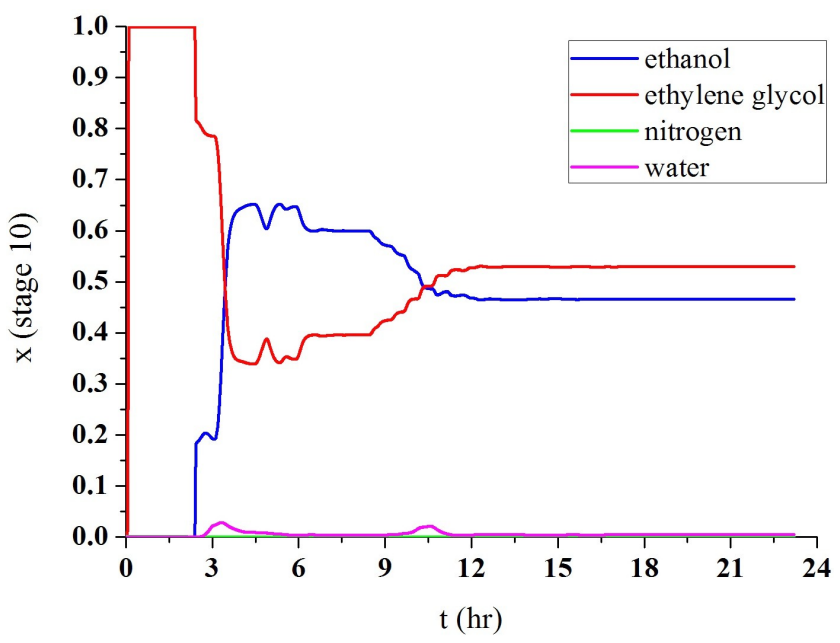

(a)

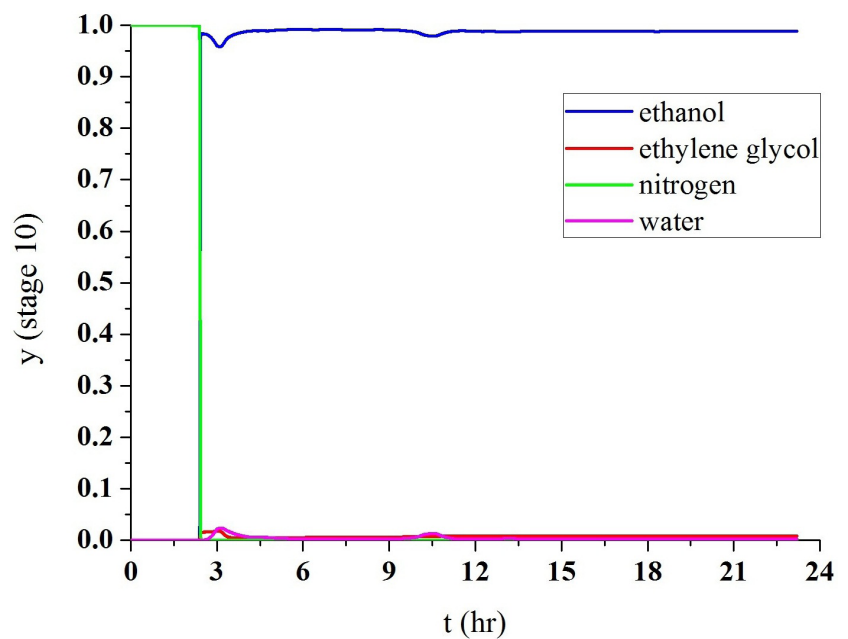

(b)

Figure 10. Dynamic behavior of the (a) liquid mole fraction and (b) vapor mole fraction in stage 10 in the rectification section of COL1.

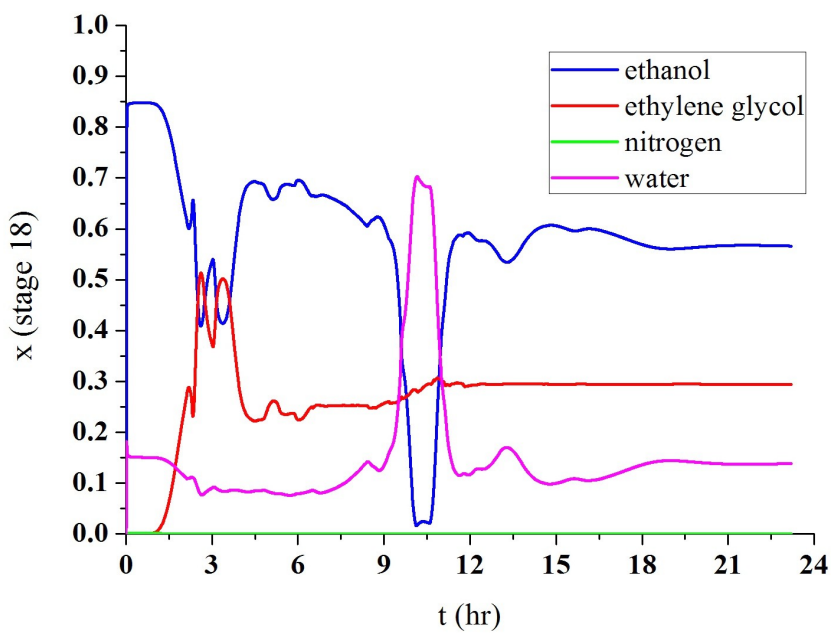

(a)

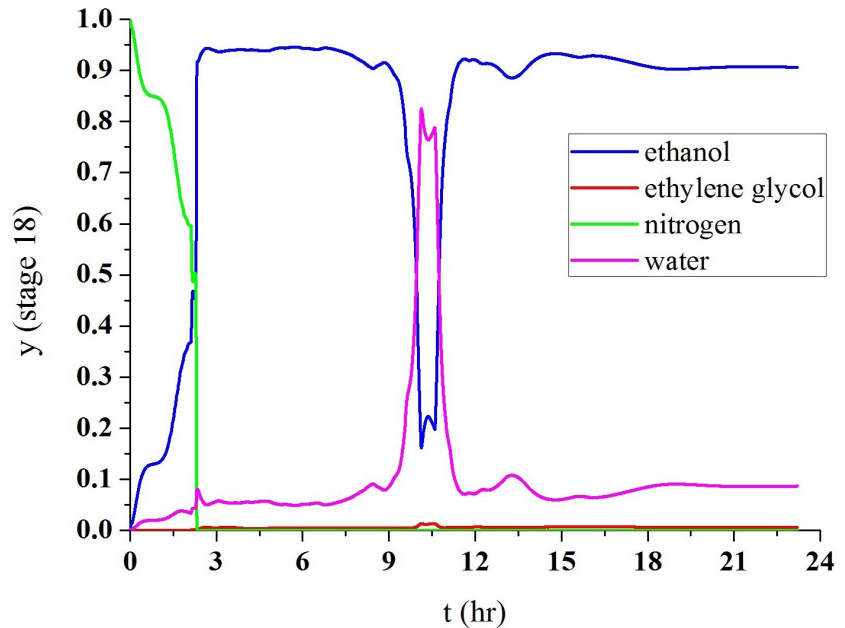

(b)

Figure 11. Dynamic behavior of the (a) liquid mole fraction and (b) vapor mole fraction in stage 18 in the stripping section of COL1. 
exhibit, in their dynamic behavior, disorders larger than those shown in the rectification section of the column.

By comparing Figure 7(b) with Figures 11(a), 12(a) and 13(a), it can be observed that the molar density variation profile of the liquid mixture in the stages of the column shows a behavior similar to the profile of the variation of the mole fraction of water in each stage, since the molar density of water is greater than that of ethanol and ethylene glycol. Consequently, the variation profile of the liquid holdup in the stages presents a behavior similar to the molar density, since it is directly influenced by this variable.

Therefore, abrupt variations of some of the variables of the stages located in the stripping section of the extractive column are due to the variation in the mole fraction of water in the liquid mixture. This behavior is not observed in the stages located in the

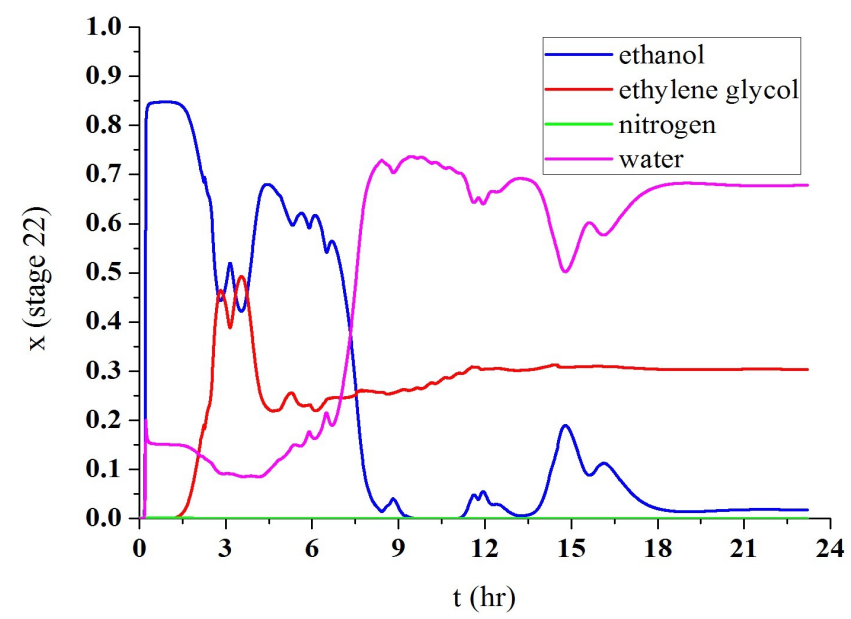

(a) rectification section, since water is practically absent in this section, as can be seen in Figure 14, which shows the mole fraction of the components in the liquid phase over the stages of the column in the steady state. From the results, it is observed that there is a large coupling between system variables.

Figure 15(a) shows the mole fraction of the components in the TOPS-1 product stream and Figure 15(b) shows the mole fraction of the components in the BOTTOM-1 product stream of the column 1 .

\section{Dynamic behavior of column 2 (COL2)}

Figure 16(a) shows the dynamic behavior of the temperature of the stages in the recovery column (COL2) during the startup operation. Figure 16(b) shows the dynamic behavior of the pressure of the stages in the recovery column (COL2) during the startup operation.

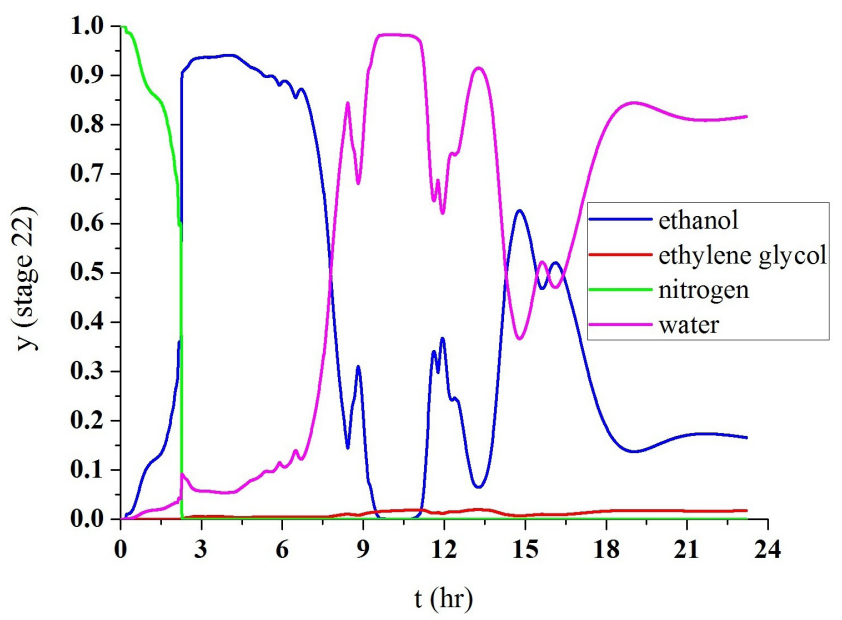

(b)

Figure 12. Dynamic behavior of the (a) liquid mole fraction and (b) vapor mole fraction in stage 22 in the stripping section of COL1.

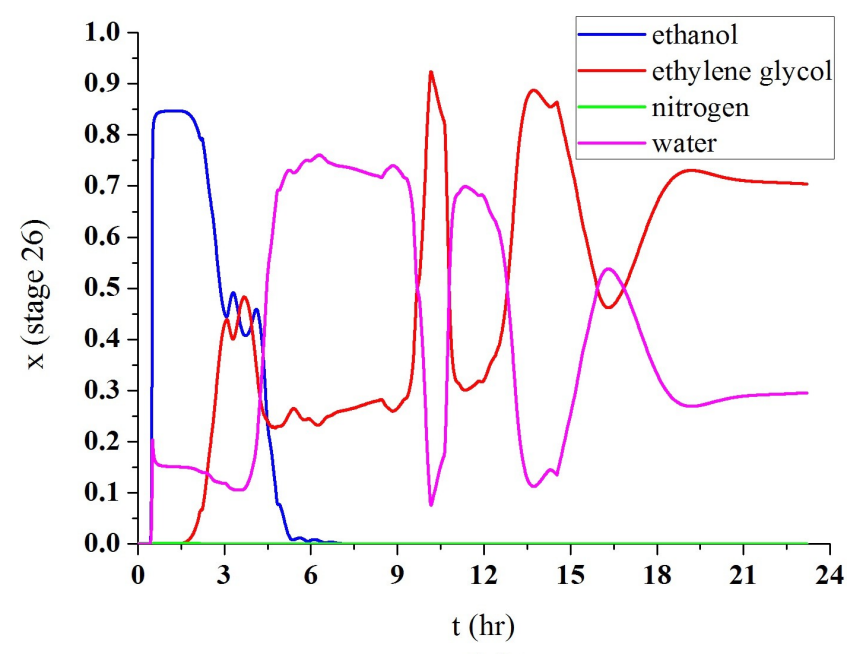

(a)

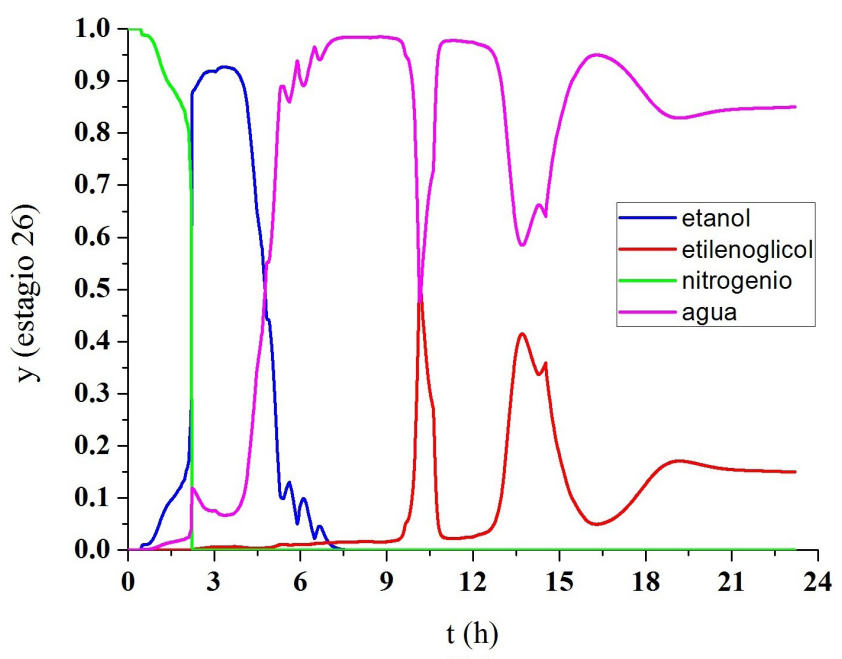

(b)

Figure 13. Dynamic behavior of the (a) liquid mole fraction and (b) vapor mole fraction in stage 26 in the stripping section of COL1. 


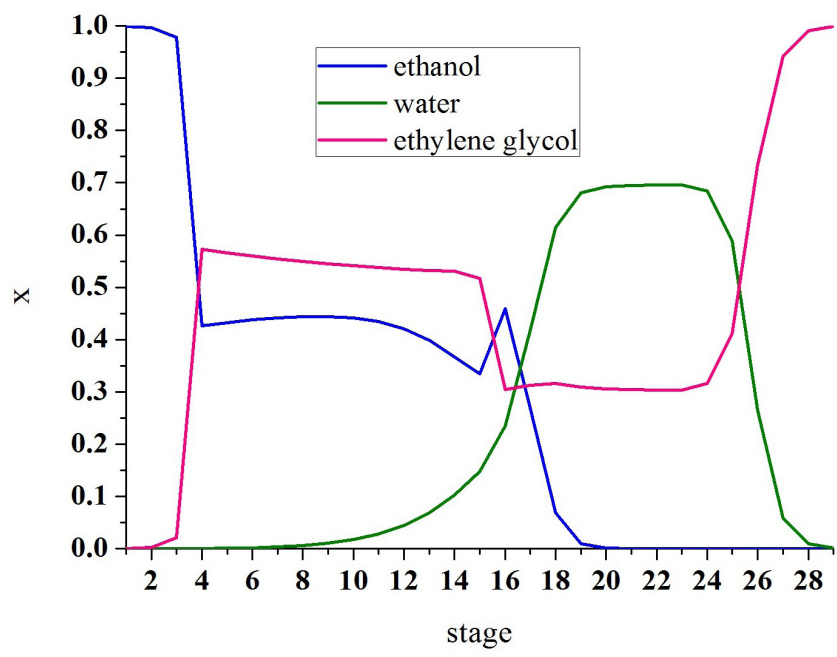

Figure 14. Mole fraction of the components in the liquid phase throughout the stages of the column in the steady state.

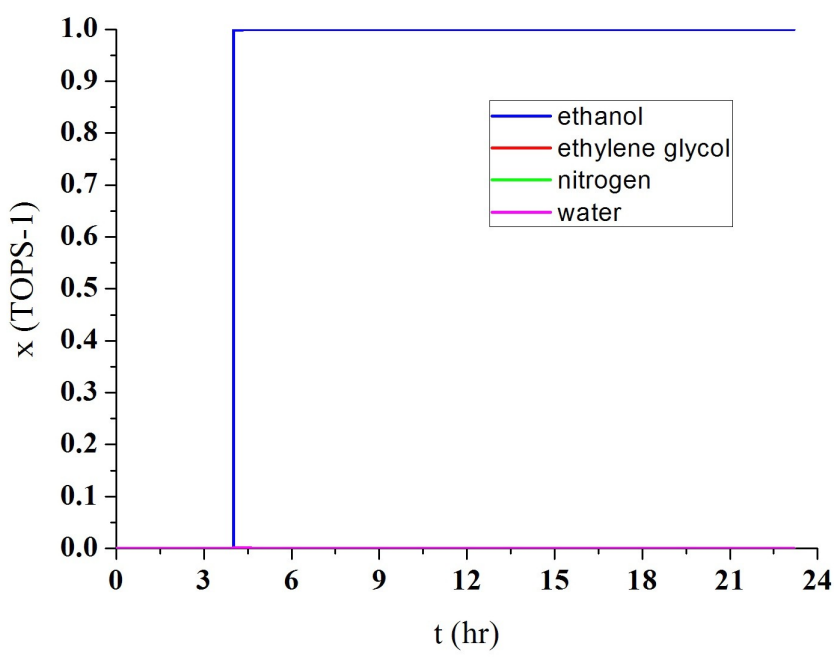

(a)
It can be observed in Figure 16(a) that the temperature of the stages in COL2, at the beginning of the startup operation of COL2, is directly influenced by the temperature variation of stage 24 in COL2, where the feed stream of COL2 is connected to COL1, as can be seen in Figure 17.

When the reflux is started in COL2, the temperature of the stages in COL2 undergoes a sudden drop, so that each stage is replaced by a different value of temperature, forming a temperature profile in COL2. Unlike COL1, COL2 does not exhibit a temperature drop at the beginning of the startup operation. This can be explained by the fact that COL2 is fed only with vapor and thus the vapor pressure in the stages of the column reaches the equilibrium values in the first few moments of the startup operation.

It is observed in Figure 16(b) that, at the beginning of the startup operation of COL2, the pressure of the

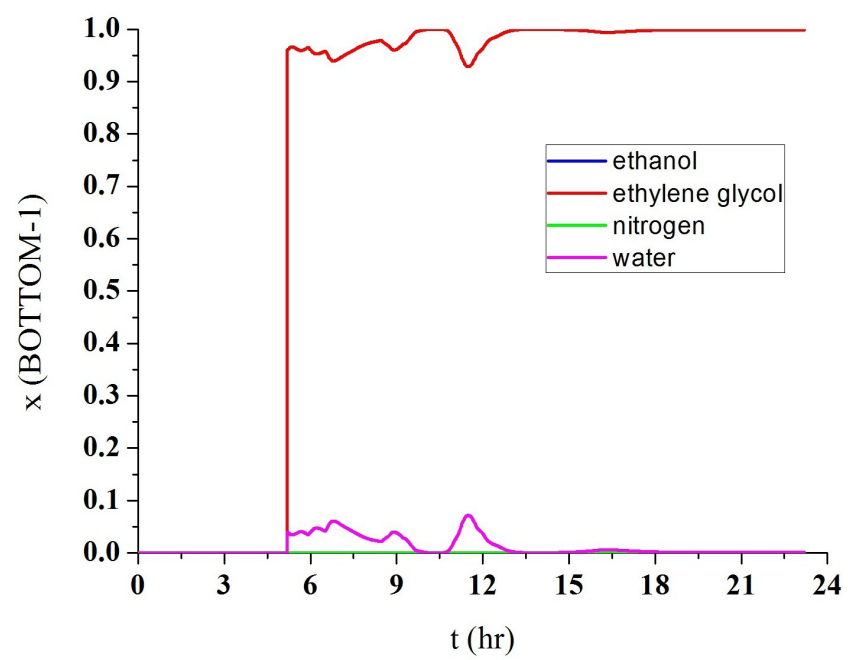

(b)

Figure 15. Mole fraction of the components in the (a) TOPS-1 and (b) BOTTOM-1 product streams of COL1.

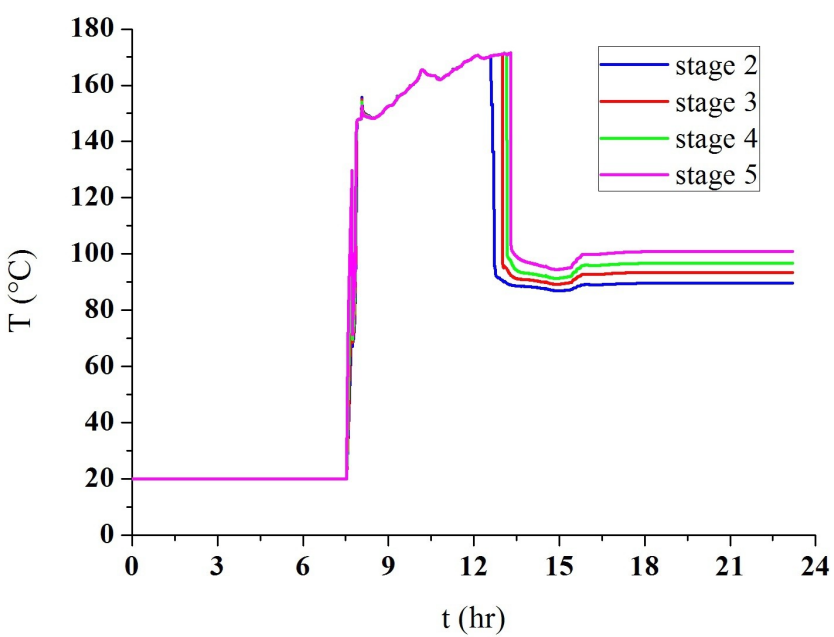

(a)

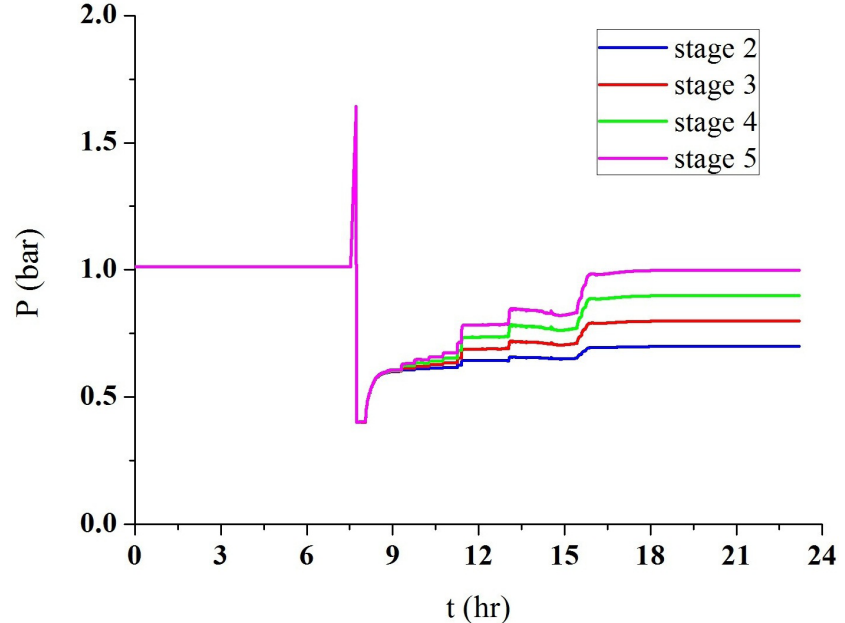

(b)

Figure 16. Dynamic behavior of (a) Temperature and (b) Pressure of the stages in COL2. 


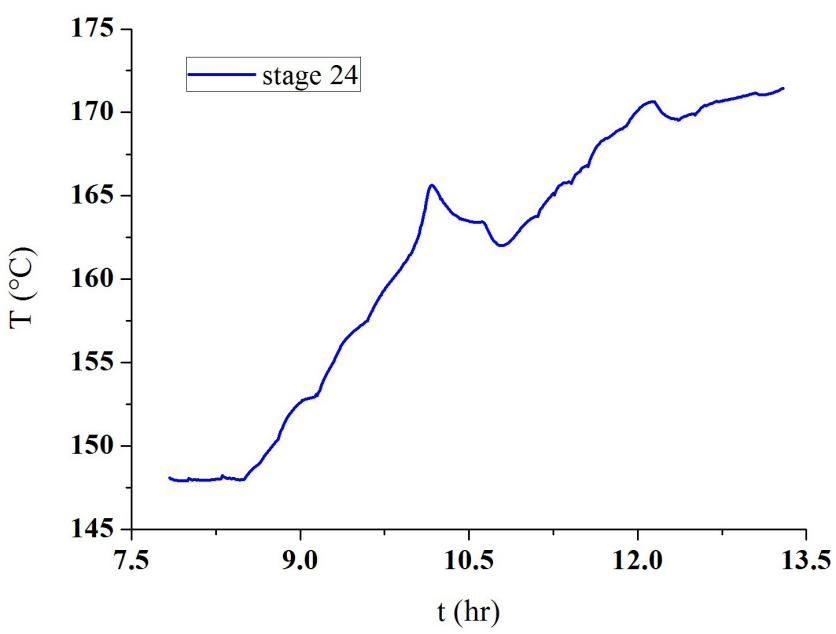

Figure 17. Temperature Profile of stage 24 in COL1.

stages increases and, right after, undergoes a sharp decrease due to the opening of the nitrogen purge valve. When the purge valve is closed, the pressure of the stages in the column increases until they reach their respective steady state values. The pressure drop between the stages increases as the liquid begins to fill the trays in COL2.

Figure 18(a) shows the dynamic behavior of the vapor flow ascending in COL2 during the startup operation. Figure 18(b) shows the dynamic behavior of the liquid flow descending in COL2 during the startup operation.

It can be seen that the vapor flow in COL2 shows an upward trend until the time that the reflux is started in COL2 and the liquid flow in the stages of COL2 begins to increase. At this moment, the vapor flow undergoes a slight decline and then increases again, until it reaches the steady state value. The liquid flow in the stages of COL2 decreases due to the reduction and adjustment of the reflux flowrate in COL2 to the steady state value. The liquid flow in stage 5 of COL2

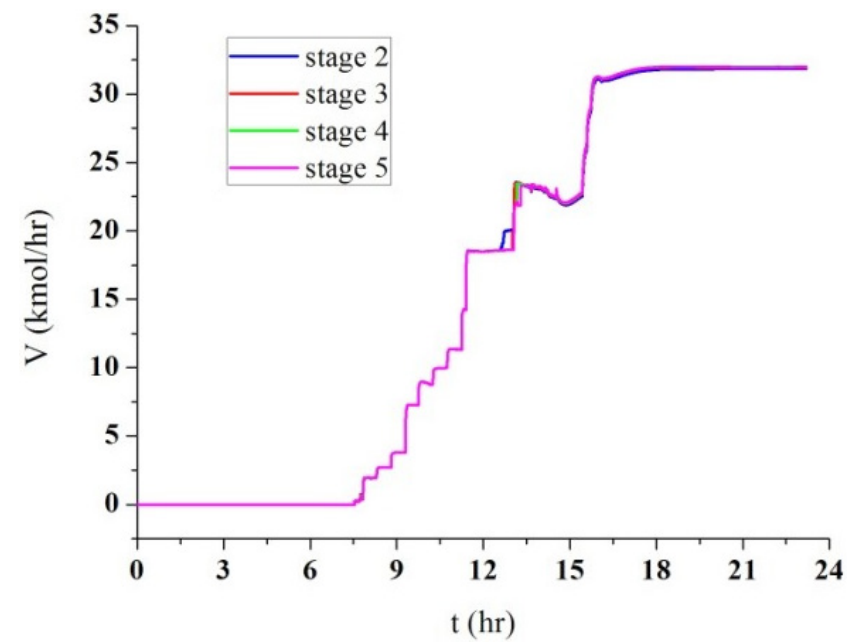

(a) corresponds to the flow of the stream LIQ that returns to COL1.

Figure 19 shows the dynamic behavior of the liquid holdup in the stages of the column. It is observed that the liquid holdup in stage 5 of COL2 is much higher than in the other stages, since stage 5 corresponds to the base of COL2.

Figure 20 and 21 shows the dynamic behavior of the mole fraction in stages 2 and 5 of COL2, respectively. It is observed that, at the beginning of the startup operation of COL2, part of the vapor feeding COL2 condenses, as observed in Figures 20(a) and 21(a). Unlike in COL1, abrupt variations in the mole fraction of water were not observed in COL2 and, consequently, in the other variables of COL2.

Figure 20(b) shows that the presence of ethanol in COL2 delays the startup operation and that the specification of the overhead stream of COL2 is achieved only when all the ethanol is eliminated from the column. Since ethanol is the most volatile

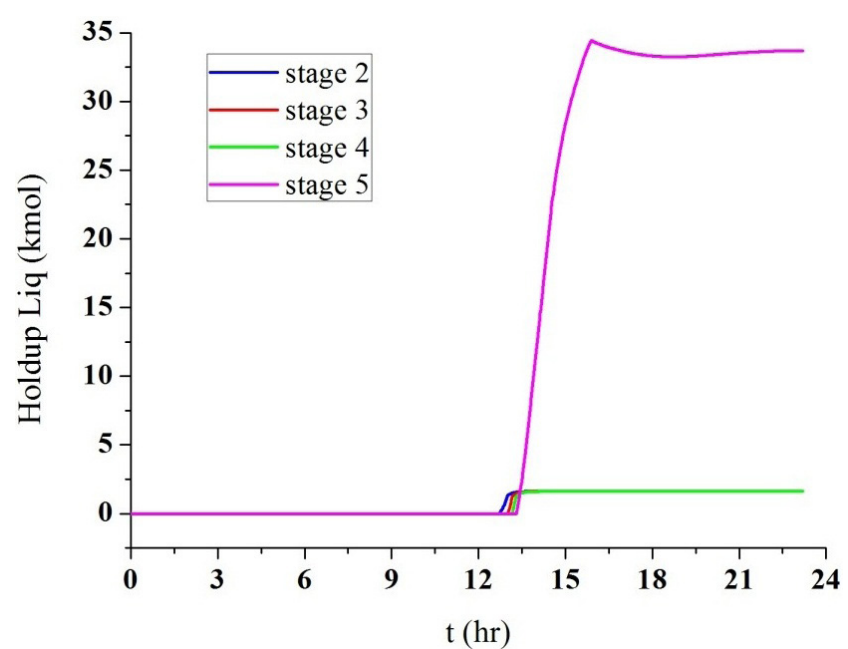

Figure 19. Dynamic behavior of the liquid holdup of the stages in COL2.

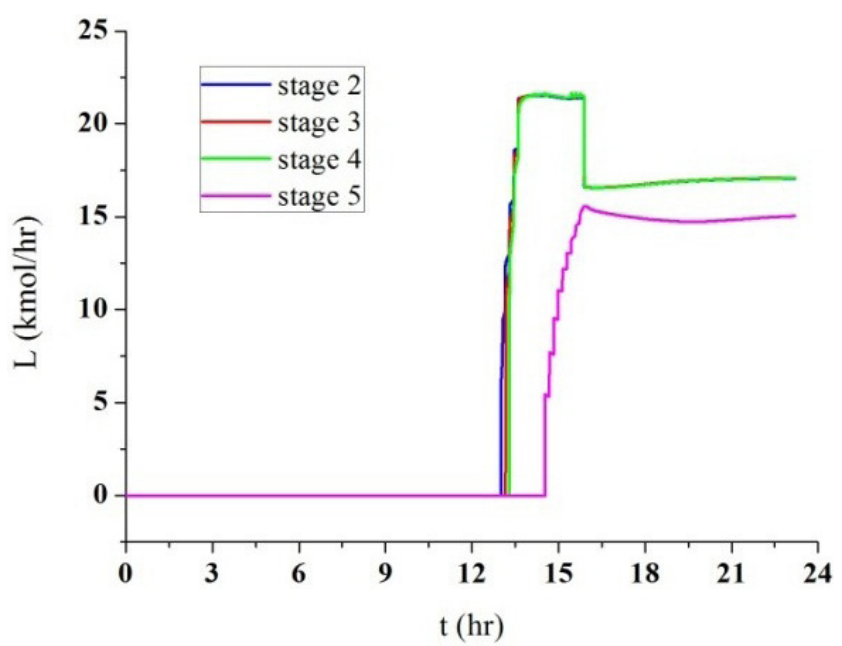

(b)

Figure 18. Dynamic behavior of (a) Vapor flowrate and (b) Liquid flowrate of the stages in COL2. 


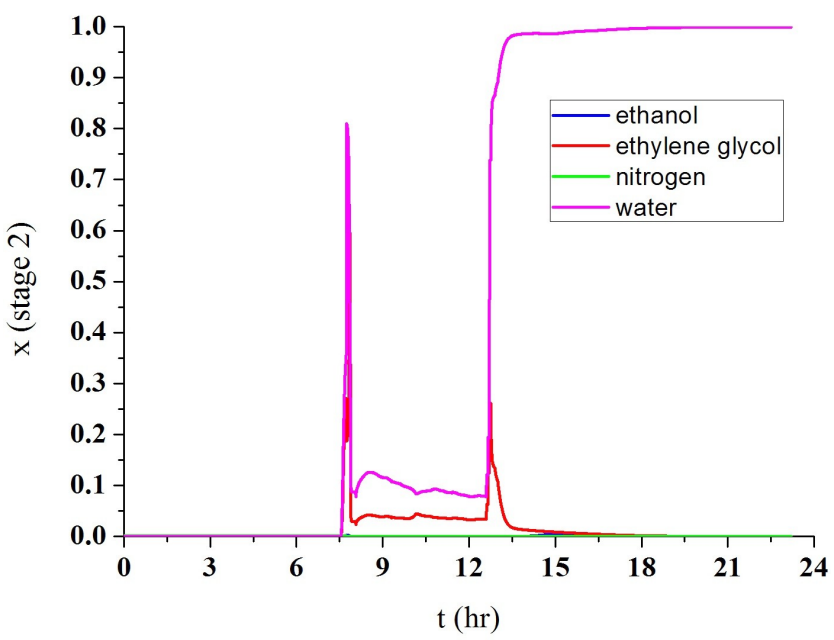

(a)

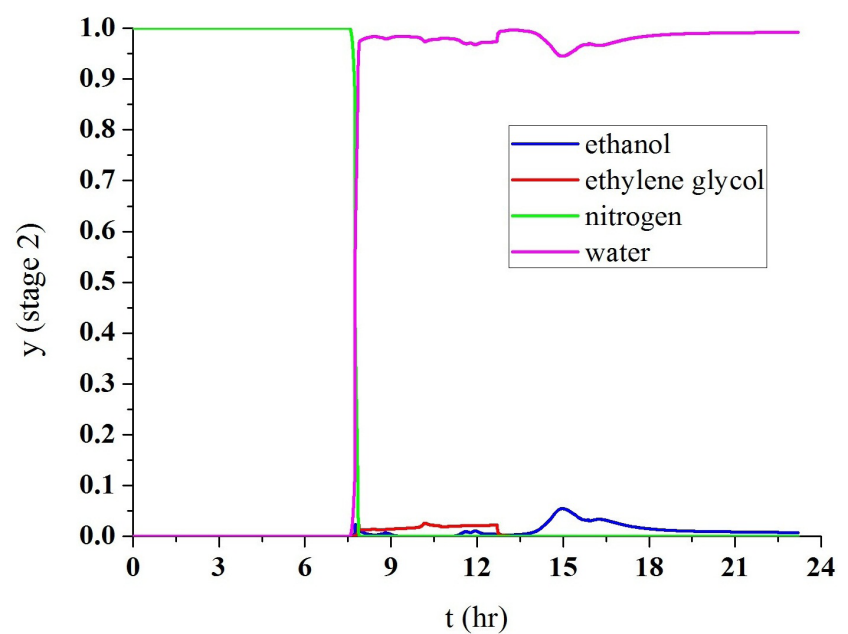

(b)

Figure 20. Dynamic behavior of the (a) liquid mole fraction and (b) vapor mole fraction in stage 2 of COL2.

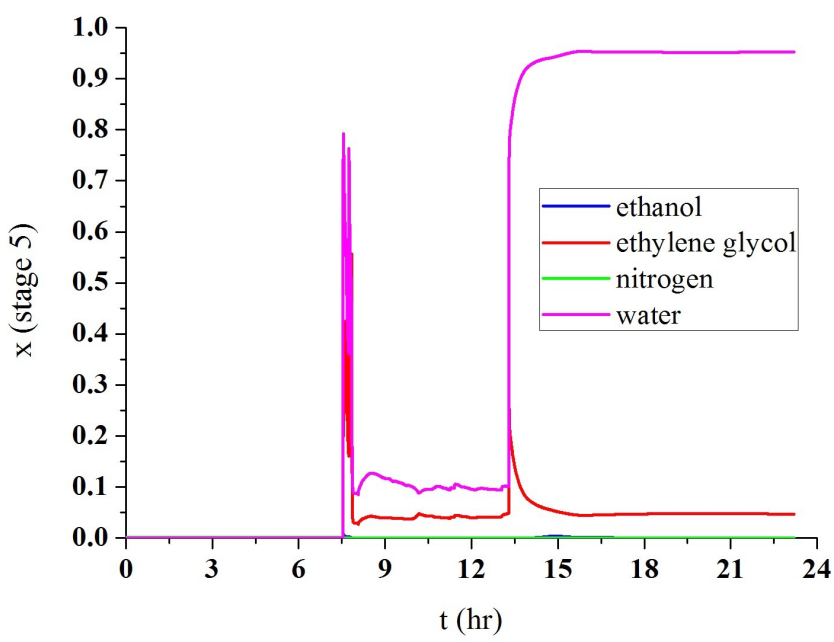

(a)

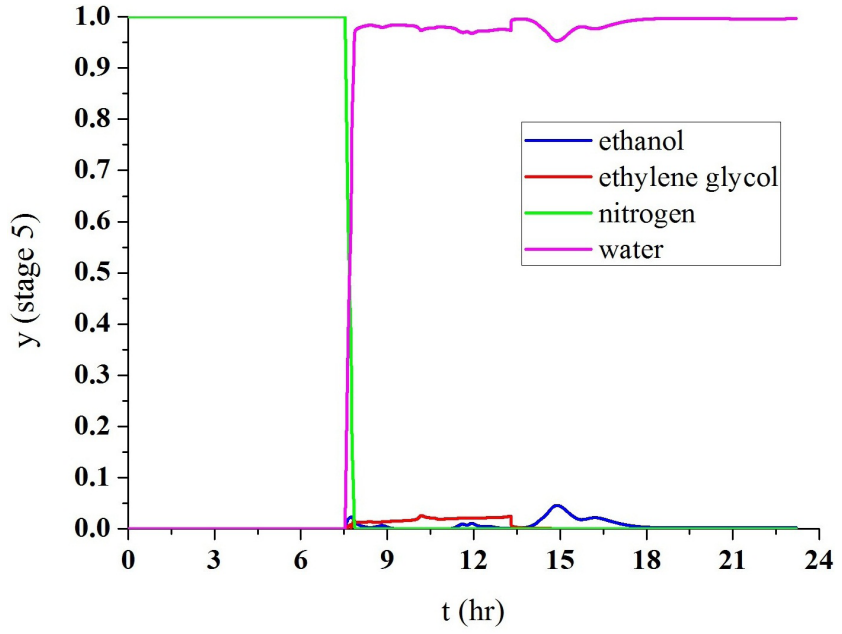

(b)

Figure 21. Dynamic behavior of the (a) liquid mole fraction and (b) vapor mole fraction in stage 5 of COL2.

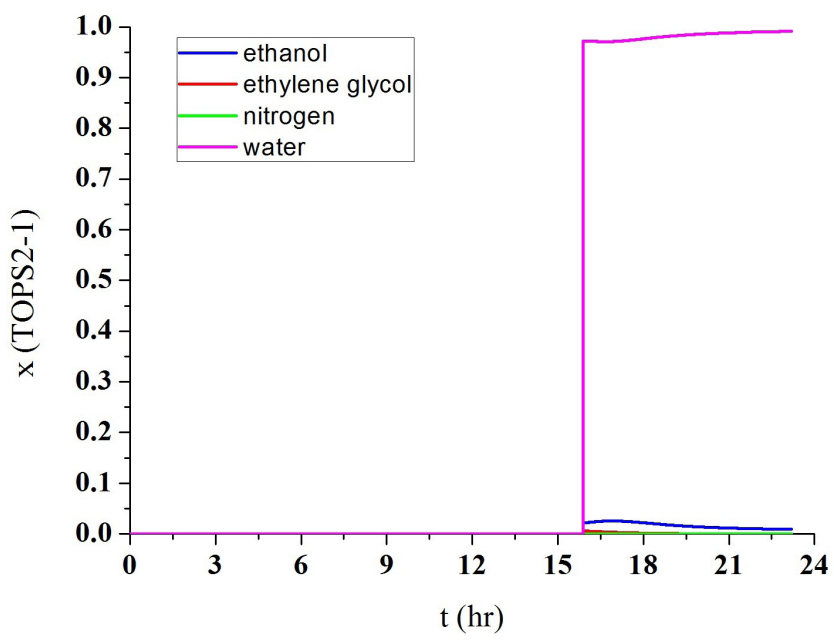

Figure 22. Mole fraction of the components in the TOPS2-1 product stream of COL2.

component, when entering into COL2, it ascends rapidly and the highest values of the mole fraction of ethanol are observed in stage 2, in the condenser and in the reflux vessel of COL2.

This detail explains the fact that the PP2 procedure had a longer startup time. In other words, in the procedure PP2 the feed from column 2 was started before the vapor present in column 1 had come close to the steady state conditions. Therefore, a good amount of ethanol followed onto column 2, which made it difficult to finalize the startup procedure of this column.

Figure 22 shows the mole fraction of the components in the TOPS2-1 product stream of column 2 .

\section{CONCLUSIONS}

From the modeling and simulation of a thermally coupled extractive distillation system to obtain anhydrous ethanol, it was possible to develop an appropriate startup procedure for the system and 
analyze the complex dynamic behavior of the main variables. The complexity of the startup operation becomes greater when the system is composed of two distillation columns interconnected by two streams, one in the vapor phase and another one in the liquid phase, as in the case of the studied system. From the analysis of the dynamic behavior of the system, greater variations were observed in the variables of the stages located in the stripping section of the extractive column. These variations are due to the variation of the liquid mixture molar density, resulting from fluctuations in the mole fraction of water in the liquid mixture, because the molar density of water is greater than the molar densities of ethanol and ethylene glycol. In this work, two startup procedures named PP1 and PP2 were presented. In the PP1 procedure, the startup of the solvent recovery column was initiated only when the conditions of the vapor, present in stage 24 of the extractive column, were close to the steadystate conditions. According to the criterion used to determine the startup time, in the procedure PP1, the top and bottom streams of the extractive column reached the specifications in 3.45 and 12.76 hours of startup respectively, while the recovery column reached the specifications of the steady state in 22.63 hours of startup. In the PP2 procedure, the solvent recovery column startup was initiated before the steam conditions, present in stage 24 of the extractive column, were close to the steady state conditions. Then, the top and the bottom streams of the extractive column reached the specifications in 3.45 hours and 12.76 hours, respectively, while the recovery column reached the steady state specifications at 40.98 hours of startup. Therefore, the PP1 startup procedure is more appropriate for the studied system, since it is concluded in a shorter time. According to the study, the solvent recovery column determines the total startup time of the system. In addition, it can be concluded that the beginning of the recovery column startup operation should only be carried out when the feed vapor conditions, present in stage 24 of the extractive column, are close to the steady state conditions; otherwise the startup time of the recovery column and consequently the time of the system will increase. A determining factor that increases the recovery column startup time is the presence of ethanol, which tends to delay the startup operation since the specification of the recovery column top stream is only achieved when all the ethanol is eliminated from the column. From the procedure developed and the dynamic analysis of the variables, new procedures can be developed.

\section{NOMENCLATURE}

\section{BOTTOM BOTTOM-1}

\author{
COL1 \\ COL1 CondPC \\ COL1 DrumLC \\ COL1_SumpLC \\ $\mathrm{COL} 2$ \\ COL2_CondPC \\ COL2 DrumLC \\ COL2 2 SumpLC \\ $\mathrm{FC}$
}

FEED

FEED-1

FSC

FV

LIQ

LIQ-1

LIQ-2

PP1

PUMP

SOLVENT

SOLVENT1

TC

TOPS

TOPS-1

TOPS2

TOPS2-1

VAP

VAP-1

VBOTTOM

VENT

VENT-1

VENT2

VENT2_1

VFEED

VLIQ

VSOLVENT

VTOPS

VTOPS2 extractive distillation column pressure control of column 1 drum level control of column 1 sump level control of column 1 solvent recovery column pressure control of column 2 drum level control of column 2 sump level control of column 2 flow rate control of ethanolwater mixture

ethanol-water mixture feed stream

ethanol-water mixture feed stream

flow rate control of solvent ethylene glycol

flow rate control of vapor phase stream

stream of the liquid phase exiting column 2

stream of the liquid phase exiting pump

stream of the liquid phase exiting VLIQ valve

Startup procedure 1 pump

solvent feed stream

solvent feed stream

temperature control of

column 1

stream exiting condenser of column 1

stream exiting VTOPS valve stream exiting condenser of column 2

stream exiting VTOPS2 valve vapor phase stream exiting column 1

vapor phase stream exiting VVAP valve

bottom stream valve of column 1

nitrogen purge stream from

column 1

nitrogen purge stream from column 1

nitrogen purge stream from column 2

nitrogen purge stream from column 2

feed stream valve of column 1 liquid stream valve of column 2 solvent stream valve of column 1

top stream valve of column 1 top stream valve of column 2 
VVAP

VVENT

VVENT2

Variables
$X_{p, i}$
$X_{p, i s s}$
$\mathrm{~T}$
$\mathrm{P}$
Fo
V
$\mathrm{L}$
Holdup Liq
x
y

vapor stream valve of column 1 nitrogen purge valve of column 1 nitrogen purge valve of column 2
time (hr)
mass fraction of component $i$ in the product stream $p$
mass fraction of component $i$ in the product stream $p$ at steady state temperature $\left({ }^{\circ} \mathrm{C}\right)$
pressure (bar)
liquid flow rate in the orifices of the stages $(\mathrm{kmol} / \mathrm{hr})$
steam flow rate throughout the stages liquid flow rate throughout the stages liquid holdup throughout the stages liquid mole fraction vapor mole fraction

\section{REFERENCES}

Annakou, O. and Mizsey, P., Rigorous comparative study of energy-integrated distillation schemes, Industrial \& Engineering Chemical Research, 35 (6), 1877-1885 (1996). https://doi.org/10.1021/ ie950445+

Aspen ${ }^{\circledR}$ Help, Aspen Technology, Inc. [S.1.], (2012).

Brito, K. D., Efeito do teor de solvente sobre o custo anual total, consume específico de energia e eficiência termodinâmica na obtenção de etanol anidro via destilação extrativa: configurações convencional e termicamente acoplada. Ph.D. Thesis, Federal University of Campina Grande (2014).

Barolo, M., Guarise, G. B., Rienzi, S. and Trotta, A., On-line startup of a distillation column using generic model control, Computers and Chemical Engineering, 17(1), S349-S354 (1993). https://doi. org/10.1016/0098-1354(93)85051-M

Caballero, J. A. and Grossmann, I. E., Design Of Distillation Sequences: From Conventional to Fully Thermally Coupled Systems, Computers and Chemical Engineering, 28, 2307-2329 (2004). https://doi.org/10.1016/j. compchemeng.2004.04.010

Delgado-Delgado, R., Barroso-Muñoz, F. O., SegoviaHernández, J. G., Hernández-Escoto, H., CastroMontoya, A. J., Rico-Ramírez, V. and Hernández, S., Multiple Steady States in Thermally Coupled Distillation Sequences: Revisiting the Design, Energy Optimization, and Control, Industrial \& Engineering Chemistry Research, 53(44), 1751517521 (2014). https://doi.org/10.1021/ie502748d
Dunnebier, G. and Pantelides, C. C., Optimal Design of Thermally Coupled Distillation Columns, Industrial Engineering Chemical and Research, 38, 162-176 (1999). https://doi.org/10.1021/ie9802919

Eden, M. R., Koggersbol, A., Hallager, L. and Jorgensen, S. B., Dynamics and control during startup of heat integrated distillation column, Computers \& Chemical Engineering, 24 (2-7), 1091-1097 (2000). https://doi.org/10.1016/S00981354(00)00488-9

Elgue, S., Prat, L, Cabassud, M., Le Lann, J. M. and Cézerac, J., Dynamic models for start-up operations of batch distillation columns with experimental validation, Computers \& Chemical Engineering, 28 (12), 2735-2747 (2004). https://doi.org/10.1016/j. compchemeng.2004.07.033

Errico, M., Rong, B., Tola, G. and Spano, M., Optimal Synthesis of Distillation Systems for Bioethanol Separation, Part 1: Extractive Distillation with Simple Columns, Industrial \& Engineering Chemistry Research, 52 (4), 1612-1619 (2013). https://doi.org/10.1021/ie301828d

Figueirêdo, M. F., Efeito do teor de solvente sobre a separação e o consumo de energia no processo de destilação extrativa. Ph.D. Thesis, Federal University of Campina Grande (2013).

Flender, M., Fieg, G. and Wozny, G., Classification of new product changeover strategy (NPS) for different application of distillation columns, Computers and Chemical Engineering, 20 (1996). https://doi.org/10.1016/0098-1354(96)00196-2

Gutiérrez-Guerra, R., Segovia-Hernández, J. G. and Hernández, S., Reducing energy consumption and $\mathrm{CO} 2$ emissions in extractive distillation, Chemical Engineering Research and Design, 87 (2), 145-152 (2009). https://doi.org/10.1016/j. cherd.2008.07.004

Hadrich, B. and Kechaou, N., Identification of Best Model for Equilibrium Data of Ethanol-Water Mixture, Journal of Chemistry and Chemical Engineering, 4 (31), 46-48 (2010).

Haydary, J. and Pavlík, T., Steady-State and dynamic simulation of crude oil distillation using Aspen Plus and Aspen Dynamics, Petroleum \& Coal, 51 (2), 100-109 (2009).

Kister, H. Z., Distillation Operation, McGraw-Hill, Inc (1990).

Kruse, C., Fieg, G. and Wozny, G., A new timeoptimal strategy for column startup and product changeover, Journal of Process Control, 6 (2-3), 187-193 (1996). https://doi.org/10.1016/09591524(95)00044-5

Niggemann, G., Gruetzmann, S. and Fieg, G., Distillation startup of fully thermally coupled distillation columns: theoretical examinations, Symposium Series, 152, 800-808 (2006). 
Petlyuk, F. B., Platonov, V. M. and Slavinskii, D. M., Thermodynamically Optimal Method for Separating Multicomponent Mixtures, International Chemical Engineering, 5, 555-561 (1965).

Reepmeyer, F., Repke, J. U. and Wozny, G., Analysis of the Start-up Process for Reactive Distillation, Chemical Engineering \& Technology, 26 (1), 8186 (2003). https://doi.org/10.1002/ceat.200390012

Ruiz, C. A., Cameron, I. T., Gani, R., A generalized dynamic model for distillation columns-III. Study of startup operations, Computers \& Chemical Engineering, 12 (1), 1-14 (1988). https://doi. org/10.1016/0098-1354(88)85001-4

Scenna, N. J., Benz, S. J., Rodríguez, N. H. and Klaric, J. I., Startup of Homogeneous Azeotropic Distillation Sequences with Multiple Steady States, Industrial \& Engineering Chemistry Research, 44 (24), 9208-9220 (2005). https://doi.org/10.1021/ ie $050004 \mathrm{i}$

Souza, W. L. R., Estudo do desempenho de uma coluna de destilação recheada na produção de etanol anidro usando glicerol como solvente. Master's Thesis, Federal Rural University of Rio de Janeiro (2012).

Sorensen, E. and Skogestad, S., Comparison of regular and inverted batch distillation, Chemical Engineering, 51 (22), 4949-4962 (1996a). https:// doi.org/10.1016/0009-2509(96)00287-4

Sorensen, E. and Skogestad, S., Optimal startup procedures for batch distillation, Computers Chem. Eng., 20, S1275-S1262 (1996b). https://doi. org/10.1016/0098-1354(96)00217-7

Steinmacher, F. R., Marangoni, C., Machado, R. A. F. and Araújo, P. H. H., Efeito das condições de alimentação sobre o procedimento de partida de uma coluna de destilação, VI Congresso Brasileiro de Engenharia Química em Iniciação Científica (2005).

Tavares, L. A. and Silva Filho, A. A., A manutenção como uma atividade corporativa, $15^{\circ}$ Congresso Brasileiro de Manutenção (2000).

Triantafyllou, C. and Smith, R., The Design and Optimization Of Fully Thermally Coupled Distillation Columns, Transactions of the Institution of Chemical Engineers, 70, p. 118 (1992).

Van Duc Long, N. and Lee, M., Optimal retrofit design of extractive distillation to energy efficient thermally coupled distillation scheme, AIChE Journal, 59 (4), 1175-1182 (2013). https://doi. org/10.1002/aic.13906

Wang, L., Li, P., Wozny, G. and Wang, S., A startup model for simulation of batch distillation starting from a cold state, Computers \& Chemical Engineering, 27 (10), 1485-1497 (2003). https:// doi.org/10.1016/S0098-1354(03)00094-2

Wendt, M., Königseder, R., Li, P. and Wozny, G., Theoretical and Experimental Studies on Startup Strategies for a Heat-Integrated Distillation Column System, Chemical Engineering Research and Design, 81 (1), 153-161 (2003). https://doi. org/10.1205/026387603321158311

Weng, K. and Lee, H., Dynamic start-up policies of extractive distillation for dehydration of iso-propyl alcohol process, The $5^{\text {th }}$ International Symposium on Advanced Control of Industrial Processes (2014).

Werle, L. O., Marangoni, C., Steinmacher, F. R., Araújo, P. H. H. and Machado, R. A. F., Application of a new startup procedure using distributed heating along distillation column, Chemical Engineering and Processing: Process Intensification, 48 (1112), 1487-1494 (2009). https://doi.org/10.1016/j. cep. 2009.10 .010

Wittgens, B. and Skogestad, S., Evaluation of dynamic models of distillation columns with emphasis on the initial response, Modeling, Identification and Control, 21 (2), 83-103 (2000). https://doi. org/10.4173/mic.2000.2.2

Wozny, G. and Li, P., Optimisation and Experimental Verification of Startup Policies for Distillation Columns, Computer Aided Chemical Engineering, 10, 493-498 (2004). https://doi.org/10.1016/S15707946(02)80110-9

Yasuoka, H., Nakanisshi, E. and Kunugita, E., Design of an online startup system for a distillation column based on a simple algorithm. International Chemical Engineering, 27, 466 (1987).

Yeomans, H. and Grossmann, I., Optimal design of complex distillation column using rigorous tray-bytray disjunctive programming models, Industrial \& Engineering Chemical Research, 39 (11), 43264335 (2000). https://doi.org/10.1021/ie0001974 